\title{
Functional Reorganization of a Prefrontal Cortical Network Mediating Consolidation of Trace Eyeblink Conditioning
}

\author{
Shoai Hattori, ${ }^{\star}$ Taejib Yoon, ${ }^{\star}$ John F. Disterhoft, ${ }^{\dagger}$ and Craig Weiss ${ }^{\dagger}$ \\ Department of Physiology and Interdepartmental Neuroscience Program, Northwestern University Feinberg School of Medicine, Chicago, Illinois 60611
}

\begin{abstract}
The medial prefrontal cortex ( $\mathrm{mPFC}$ ) has been studied for its role in various cognitive functions, but the roles of its subregions remain unclear. We performed tetrode recordings simultaneously from prelimbic (PL) and rostral (rACC) and caudal (cACC) anterior cingulate subregions of the rabbit $\mathrm{mPFC}$ to understand their interactions during learning and tests of remote memory retention for whiskersignaled trace eyeblink conditioning. cACC neurons exhibited an innate response to the conditioning stimulus (CS) that rapidly decreased across sessions, suggesting an attentional role for facilitating CS-US associations. rACC neurons from conditioned rabbits exhibited robust responses to the CS that decreased within each session, possibly evaluating its emotional salience. PL neurons exhibited robust persistent activity during the trace interval during tests of remote memory retention, suggesting its involvement in retrieval and execution of a consolidated response. Mechanistically, conditioning was associated with a greater percentage of persistently responsive neurons than neurons from pseudoconditioned control rabbits, and responses differed significantly between trials with and without conditioned responses. Collectively, these responses reflect a functional reorganization of neural activity within the prefrontal network from an attentional mode to one that orchestrates the retrieval and execution of the learned response.
\end{abstract}

Key words: anterior cingulate cortex; hippocampus; medial prefrontal cortex; memory acquisition; persistent firing; prelimbic cortex

\section{Introduction}

The medial prefrontal cortex (mPFC) has been investigated widely for its roles in various cognitive functions, including decision making, error detection, executive control, and memory (Euston et al., 2012). With respect to mnemonic processes, what is known has come mainly from examination of human amnesics and animal lesion studies. These studies have led to two general views regarding the longitudinal function of the $\mathrm{mPFC}$ during memory processes: (1) the $\mathrm{mPFC}$ becomes selectively responsive for memories that were initially mediated by the hippocampus and is essential for the retrieval of remotely but not recently acquired memories (Takehara et al., 2003; Frankland and Bontempi, 2006; Takehara-Nishiuchi and McNaughton, 2008); and (2) the mPFC plays a global role in the encoding, consolidation, and retrieval of remotely acquired memories and thus is involved during both recently and remotely acquired memories (Blum et al., 2006; Corcoran and Quirk, 2007; Lee and Solivan, 2008; Quinn et al., 2008; Churchwell et al., 2010). Specifically, studies

\footnotetext{
Received 0ct. 14, 2013; revised Dec. 6, 2013; accepted Dec. 11, 2013.

Author contributions: S.H., J.F.D., and C.W. designed research; S.H., T.Y., and C.W. performed research; S.H., T.Y., J.F.D., and C.W. analyzed data; S.H., T.Y., J.F.D., and C.W. wrote the paper.

This work was supported by National Institute of Mental Health Grants F31MH099769 (S.H.) and R01MH47340 (J.F.D.), National Institute on Aging Grants 5T32AG020418 (S.H.) and 5T32AG020506 (T.Y.), and National Institute of Neurological Disorders and Stroke Grant R01NS059879 (C.W.). We thank Lillian Chen, James Baker, and Alfred Rademaker of the Northwestern University Biostatistics Collaboration Center for help with data analysis.

The authors declare no competing financial interests.

*S.H. and T.Y. contributed equally to this work.

${ }^{\dagger} J$ J.F.D. and C.W. contributed equally to this work.

Correspondence should be addressed to Craig Weiss, 303 East Chicago Avenue, Ward Building Room 7-140, Chicago, IL 60611. E-mail: cweiss@northwestern.edu.

DOI:10.1523/JNEUROSCI.4428-13.2014

Copyright $\odot 2014$ the authors $\quad 0270-6474 / 14 / 341432-14 \$ 15.00 / 0$
}

have suggested that the mPFC is essential for the assimilation of new memories into preexisting networks of knowledge, known as schemas, through cognitive and/or strategic control over memory processes within other brain areas during memory acquisition and consolidation (Moscovitch, 1992; Buckner and Wheeler, 2001; Miller and Cohen, 2001; Dobbins et al., 2002; Postle, 2006; Preston and Eichenbaum, 2013). This process may be mediated by various functions, such as working memory, attentional modulation, and evaluative mechanisms that are designated to specific regions within the $\mathrm{mPFC}$.

A paradigm used to examine neural substrates for associative memory and that has contributed support for these views is trace eyeblink conditioning (EBC; Christian and Thompson, 2005; Kalmbach et al., 2009; Weiss and Disterhoft, 2011). It pairs an initially neutral conditioning stimulus (CS) with an aversive unconditioned stimulus (US) to the eye or periorbital region after a stimulus-free trace interval. Repeated noncontiguous pairings of the two stimuli elicit a conditioned blink response (CR), the behavioral assay for memory. Some mPFC lesion studies using trace $\mathrm{EBC}$ have provided evidence for $\mathrm{mPFC}$ involvement during remote memory retrieval, whereas others contend involvement during both recent and remote time points. The disparate findings are likely attributable to a functional segregation among the mPFC subregions, including the prelimbic (PL) and rostral (rACC) and caudal (cACC) anterior cingulate cortices, and the time at which data were examined relative to the time of learning.

Specifically, trace EBC acquisition was impaired by permanent or reversible pretraining lesions of the cACC (KronforstCollins and Disterhoft, 1998; Weible et al., 2000; Kalmbach et al., 2009), and the physiological responses were most robust during the initial trials and sessions of conditioning (Weible et al., 2003), 
leading to views that the cACC may play a role in modulation of attention. Conversely, retention of remotely acquired trace EBC was impaired by PL lesions performed 1 week but not immediately after learning (Oswald et al., 2008, 2010), suggesting its role in remote memory storage and expression. Pretraining lesions of the rACC impaired extinction of trace EBC (Weible et al., 2000) but did not affect acquisition, suggesting an evaluative role for the rACC.

These studies suggest a functional segregation of mPFC subdivisions that would be accompanied by subregion-specific changes in neuronal activity as learning evolves and memory consolidates, a process we will hereafter refer to as a functional reorganization of neuronal activity within the MPFC network. However, no study has examined neuronal activity within the subregions of the mPFC network simultaneously and longitudinally during recent and remote time points and in comparison to the neuronal activity of control animals. Thus, whether differential activation patterns of distinct $\mathrm{mPFC}$ areas support the proposed functions of these $\mathrm{mPFC}$ regions during successive stages of learning and memory remain unclear.

Here we report multiple single-neuron activity recorded simultaneously from the rabbit PL, rACC, and cACC during acquisition of whisker-signaled trace $\mathrm{EBC}$ and during retention sessions administered after a 1 month training-free hiatus. Results provide evidence for a learning and memory-dependent functional reorganization of neuronal activity within the mPFC network.

\section{Materials and Methods}

Subjects. Subjects were 14 young adult, female New Zealand White rabbits, 3-6 months of age (seven conditioned, seven pseudoconditioned). All subjects were individually housed and maintained on a $12 \mathrm{~h} \mathrm{light/dark} \mathrm{cycle.}$

Surgical procedure. All surgeries were performed using sterile procedures approved by the Northwestern University Institutional Animal Care and Use Committee. Rabbits were prepared as described previously (Flores and Disterhoft, 2013). Burr holes were drilled for skull screws to anchor a restraining head bolt and a 96-channel microdrive containing 24 independently moveable tetrodes and three reference tetrodes. A $4 \times$ $8 \mathrm{~mm}$ craniotomy was performed over the intended locations of recording sites into the PFC, and the dura was slit and reflected. The microdrive was then stereotaxically positioned onto the surface of the brain, and the craniotomy around the guide tubes was filled with Kwik-Sil (WPI). A screw connected to a ground wire from the electrode interface board (EIB) on the microdrive was then implanted into the skull. Dental acrylic was used to cement the microdrive and head bolt to the skull screws. Rabbits were administered $0.2 \mathrm{mg} / \mathrm{kg}$ Metacam (intramuscularly) postoperatively and the following day for analgesia.

Behavioral training. Rabbits were given at least $7 \mathrm{~d}$ of postoperative recovery and were then brought to the laboratory for acclimation to the conditioning environment inside an Industrial Acoustics sound and light attenuating chamber. During acclimation sessions, tetrodes were gradually lowered to their intended targets. Rabbits were prepared for training (Das et al., 2001), and conditioning sessions were done as reported previously (Galvez et al., 2006). The CS consisted of $250 \mathrm{~ms}$ whisker vibrations delivered at $60 \mathrm{~Hz}$ using a vibrotactile transducer. The trace interval consisted of a $500 \mathrm{~ms}$ stimulus-free interval. The US consisted of a $150 \mathrm{~ms}$ corneal air puff delivered at 3 psi. An adaptive CR was defined as a blink with a voltage amplitude exceeding the mean baseline amplitude $(250 \mathrm{~ms}$ pre-CS) by 4 SDs for $15 \mathrm{~ms}$ minimum within the $20 \mathrm{~ms}$ interval before US onset. Pseudoconditioned animals were yoked for the number of sessions with the conditioned animals and were presented with explicitly unpaired CS and US trials in random order.

Single-neuron recording. A custom-designed microdrive equipped with 24 independently movable tetrodes was used to acquire singleneuron activity simultaneously from the PL cortex (A6-A8), rACC (A5$\mathrm{A} 7)$, and cACC (A2-A5). Tetrodes were fabricated by twisting four strands of $12.7-\mu \mathrm{m}$-diameter Stablohm 800 wire together (RO-800; Cal- ifornia Fine Wire). Twisted wires were briefly heated to enhance rigidity. Tetrode tips were gold-plated to achieve an impedance of $200-500 \mathrm{k} \Omega$ at $1 \mathrm{kHz}$. During recording sessions, the drive assembly was connected to a 96-channel Cheetah data acquisition system via EIB-36 boards (Neuralynx). Neuronal signals were referenced to a common skull screw or reference tetrode. A threshold voltage was adjusted for each wire of each tetrode so that a spike exceeding the threshold triggered collection of the activity on all four wires of the tetrode for that time window. Cheetah acquisition software (Neuralynx) was used to collect neuronal data, blink amplitudes, and timestamps of CS and US presentations.

Single-neuron isolation. Activity of single neurons was separated offline using Klustakwik in the Neuralynx SpikeSort 3D program. Sorting was based on a number of different waveform parameters, including peak/ valley amplitudes, height, and spike widths. Custom scripts written in Igor (WaveMetrics) were used to calculate the ratio of signal-to-noise $(\mathrm{S} / \mathrm{N})$ of individual clusters to separate well isolated from noisy clusters. For each cluster, the waveform of each spike was divided into 32 points with the peak forced to the eighth point. The mean waveform and variance waveform were then computed for each neuron. Noise, $\mathrm{N}$, was defined as follows: $N=\sqrt{\frac{1}{n} \sum_{i=1}^{n} \sigma_{i}^{2}}$, where $n=32$ points and $\sigma^{2}$ is the variance waveform. The signal, $\mathrm{S}$, was defined as the difference between the peak and the trough in the mean waveform. The quotient of $S$ and $N$ yielded the $\mathrm{S} / \mathrm{N}$ ratio.

Neuronal clusters with $\mathrm{S} / \mathrm{N}$ ratio of at least $6.5: 1$ were included for subsequent analyses. Tetrode placement was changed only if spikes were not detected. However, given the possibility of tetrode drift and loss of signal or appearance of new neuronal spikes, neuronal clusters from each recording session were regarded as representing the activity of unique neurons for each session. The distribution of spike widths (peak-valley) and baseline firing rate for all neurons was examined to distinguish presumptive pyramidal neurons from presumptive interneurons. Results indicated a wide range of baseline firing rates with a large proportion of neurons having a rate $<15 \mathrm{~Hz}$. Although the percentage of neurons with rates $>15 \mathrm{~Hz}$ was relatively low, we found that the response profile of the population for a given region changed drastically if those neurons were included. For this reason, we excluded those neurons and focused our analyses on presumptive pyramidal neurons.

Data analyses. The total number of neurons from the current study includes the number of neurons identified for 13 sessions, including the first day of training (D1), seven sessions centered around the day of criterion $(\mathrm{C}-3, \mathrm{C}-2, \mathrm{C}-1, \mathrm{C}, \mathrm{C}+1, \mathrm{C}+2, \mathrm{C}+3)$, and five sessions of retention testing that were given after a $30 \mathrm{~d}$ training-free hiatus. Neurons from the first training session of each rabbit were analyzed to examine the innate responsiveness to novel stimuli and changes attributable to subsequent learning. The first training session was day $\mathrm{C}-3$ for three rabbits from the conditioned group; those neurons were included in both the $\mathrm{D} 1$ and $\mathrm{C}-3$ sessions.

All analyses were conducted using custom scripts written in MATLAB (MathWorks). For each neuron, a nonparametric Mann-Whitney $U$ test was used to compare the mean baseline firing rate with the neuronal activity during the subsequent $250 \mathrm{~ms} C S$ and $500 \mathrm{~ms}$ trace periods (Flores and Disterhoft, 2013). Rate-increasing (RI) and rate-decreasing (RD) neurons exhibited, respectively, significant increases or decreases in firing rate during the CS-trace period after the baseline period. The proportions of responsive neurons between the conditioned and pseudoconditioned groups were compared using a $\chi^{2}$ analysis. Neuronal activity was also compared between the groups by converting raw firing rates into $z$-scores (firing rates normalized to $2 \mathrm{~s}$ pre-CS baseline interval). Perievent time histograms (PETHs) were generated for the time interval between the $1 \mathrm{~s}$ pre-CS and $2 \mathrm{~s}$ post-CS windows using $10 \mathrm{~ms}$ bins. Both the raw firing rate and normalized $z$-scores were calculated to compare the response profiles during the trial. Statistical comparisons of changes in firing rate between the groups were performed using two-way ANOVA with training group (conditioned vs pseudoconditioned) and session as factors.

Persistent responses during a trial for each neuron were computed by first converting rasters into continuous spike density functions (SDFs). Individual spike trains were convolved using a Gaussian kernel with an $\mathrm{SD}$ of $10 \mathrm{~ms}$ (equivalent to putting a confidence interval on the spike 
times; Richmond et al., 1987). Neurons in which the absolute amplitude of the SDF exceeded 2.575 SDs ( $99 \%$ confidence) of the mean baseline SDF for $70 \%$ of the trace interval were regarded as persistently responsive. Persistently responsive neurons were further classified into RI and $\mathrm{RD}$ depending on the sign of the responses.

Response onset for each neuron among the subregions were determined from PETHs using a method reported previously (Kiani et al., 2005). PETHs with $1 \mathrm{~ms}$ bins were generated and then convolved with a $3 \mathrm{~ms}$ SD Gaussian kernel. The first of 10 consecutive bins that exceeded 1.96 SDs above the mean baseline activity defined response onset for RI neurons. For RD neurons, the threshold for determining response onset was set at $1 / 4$ SD below the mean baseline activity (to avoid a floor effect).

Histology. Marking lesions were made to locate the placement of the recording sites by passing current through individual tetrode wires $(+50$ $\mu \mathrm{A}, 5 \mathrm{~s})$ after completion of behavioral testing. Rabbits were then administered an intravenous dose of ketamine/xylazine (50 and $25 \mathrm{mg} / \mathrm{kg}$, respectively) for deep anesthesia and were perfused transcardially with $0.9 \%$ saline, followed by $10 \%$ buffered Formalin. All tetrodes were then raised to the surface of the brain, and the brain was extracted out of the skull for $24 \mathrm{~h}$ postfixation in 10\% Formalin. Subsequently, the brain was prepared for detecting marking lesions (Weiss et al., 1996). Recording sites were estimated by calculating any advancement made at the end of recording sessions with the location of the marking lesion. Any activity recorded from positions outside the area of interest was excluded from additional analyses.

\section{Results}

\section{Behavior}

Conditioned rabbits $(n=7)$ reached the behavioral learning criterion of at least eight adaptive CRs during a span of any 10 consecutive trials with an average of 4.3 sessions. Pseudoconditioned control rabbits $(n=7)$ were matched for the number of sessions with the conditioned animals and received explicitly unpaired CS-only and US-only trials in pseudorandom order.

The percentage of adaptive CRs across training sessions for both groups is shown in Figure 1A. This figure shows the data for the first day of training and other days after synchronizing the data to the day that behavioral criterion was achieved (day C). It also shows the performance of the rabbits during retention testing after they stayed in their home cages for $30 \mathrm{~d}$. Note that the initial six rabbits (three conditioned, three pseudoconditioned) in the study did not undergo retention testing. However, their behavioral performance during acquisition did not differ from rabbits that did receive retention testing.

A repeated-measures ANOVA on the percentage of trials with CRs indicated a significant interaction of group and session $\left(F_{(7,77)}=13.8, p<0.0001\right)$ because of the significant increase for the conditioned group that occurred as of session $\mathrm{C}-2(p=$ $0.056)$ and $C-1(p=0.0007)$ according to post hoc Fisher's tests; the pseudoconditioned group did not exhibit any significant change in CRs across sessions. The difference between the groups was maintained during testing for remote retention (82 vs $13 \%$ ) according to another ANOVA $\left(F_{(1,6)}=750, p<0.0001\right)$, and both groups had a plateau level of performance because neither group had a significant change in performance across the five retention testing sessions.

The average increase in the amplitude of the CRs across training sessions can be seen for the conditioned group in Figure $1 B$. Note that there are minimal blink responses to the CS for pseudoconditioned rabbits.

\section{Neuronal population and histology}

Only neurons histologically verified to be within the medial PFC and that had an $\mathrm{S} / \mathrm{N}$ ratio of at least 6.5:1 were included for analysis (see Materials and Methods). The activity of 2201 neurons from
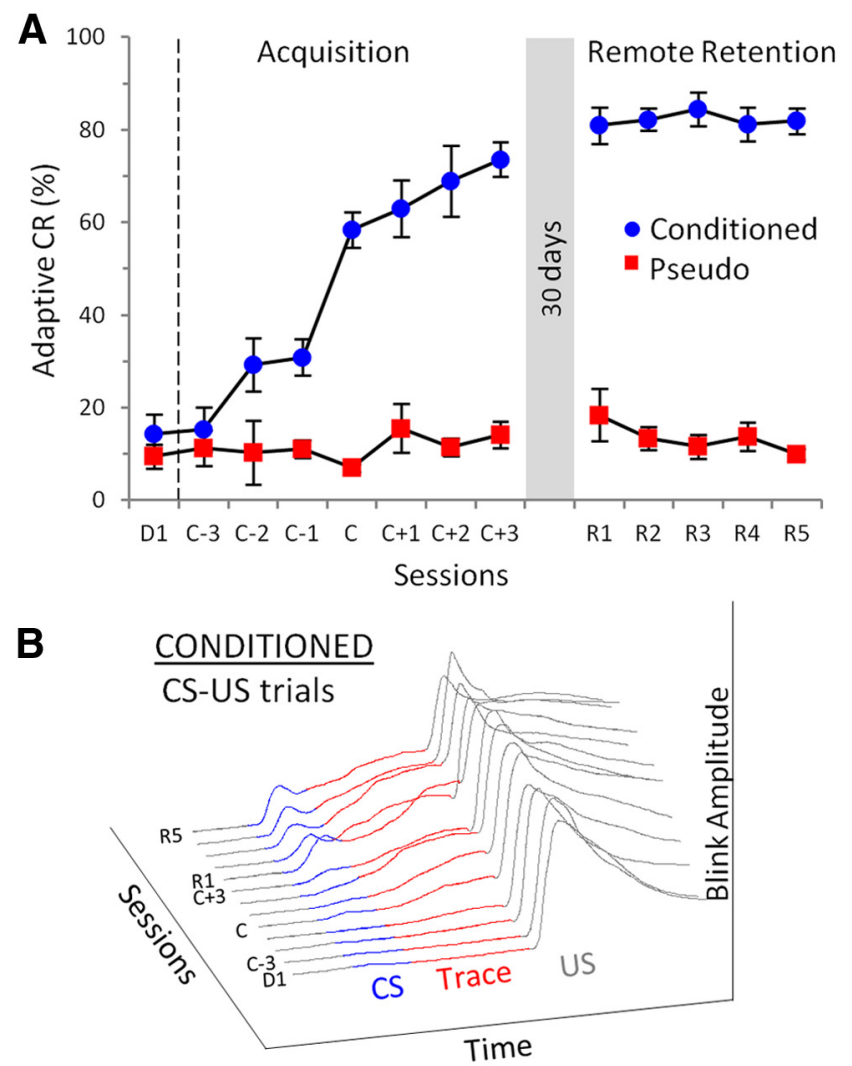

$\frac{\text { PSEUDO }}{\text { CS trials }}$

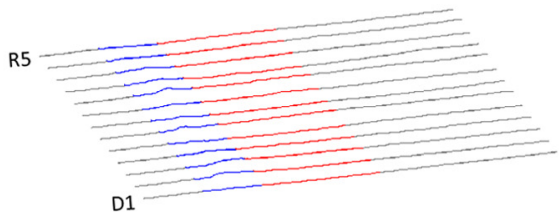

D1

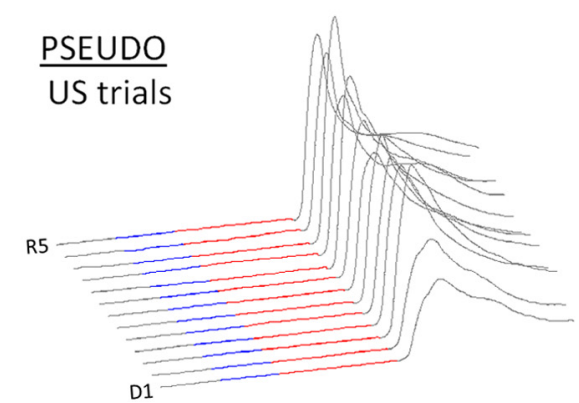

Figure 1. Paired CS-US stimuli lead to an increase in CRs. $A$, The mean percentage of trials with adaptive CRs (those that are present within $20 \mathrm{~ms}$ of US onset) are plotted as a function of training sessions during acquisition and retention testing (D1, first day of training; $C$, day of criterion; $R$, retention). Data are shown for conditioned rabbits (those that received paired whisker-puff trials) and (S-alone trials from control rabbits (those that received explicitly unpaired (S and US presentations). B, "Waterfall" behavioral plots showing the time course amplitude of the average blink for each session for the conditioned group (top), CS-alone trials of the pseudoconditioned group (middle), and US-alone trials of the pseudoconditioned group (bottom). Blue portions represent the time during which the $C S$ was presented $(250 \mathrm{~ms})$. Red portions represent the trace interval between $(S$ offset and US onset $(500 \mathrm{~ms})$. Note the increase in amplitude and the shortening in onset latency across sessions for the conditioned group. Note that data from the pseudoconditioned group have been sorted into CS-alone and US-alone trials that were presented pseudorandomly during training. 


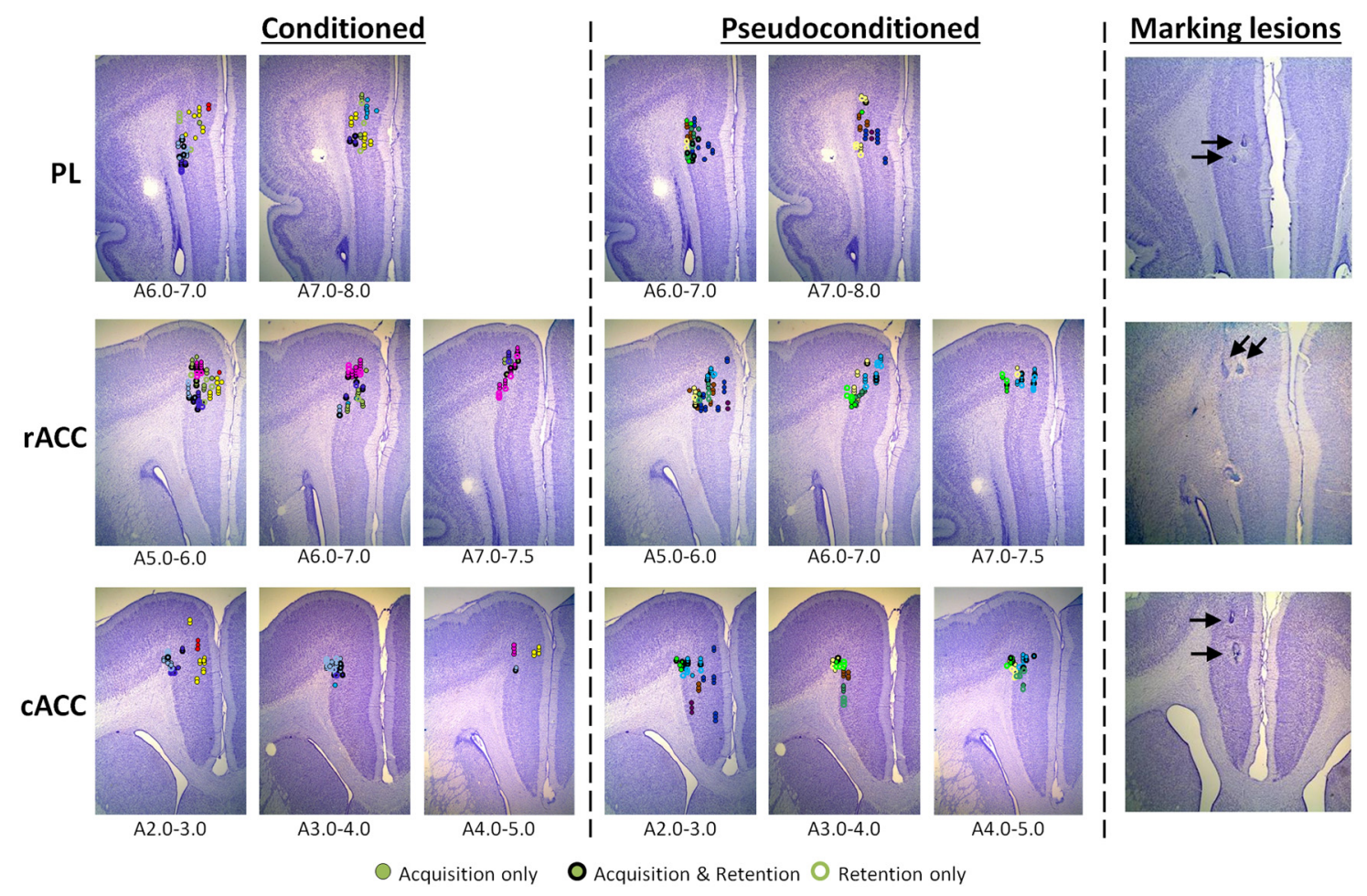

Figure 2. Histological localization of all recording sites for conditioned and pseudoconditioned control rabbits. Reconstruction of recording sites are shown segregated by region (PL, rACC, CACC) and group (conditioned, pseudoconditioned). Different marking colors represent the different rabbits used in the study. The different symbols indicate whether data were recorded during acquisition, retention, or both types of sessions. Numbers under each panel indicate approximate distance (millimeters) rostral to bregma. Three panels on the right show representative marking lesions (arrows) indicating recording sites from three respective PFC subregions.

conditioned rabbits and 2092 neurons from pseudoconditioned control rabbits were analyzed for acquisition sessions. During sessions to test retention of remote memory, we analyzed the activity of 998 neurons from conditioned rabbits and 612 neurons from pseudoconditioned rabbits. Histologically verified locations of neurons within different subregions of the PFC are shown in Figure 2. A breakdown of the number of neurons recorded by group, region, and phase of training is shown in Figure 3A. The results indicate that recordings were stable for the duration of the experiment.

A comparison of baseline firing rate and spike width was made for all the recorded neurons to distinguish pyramidal neurons from interneurons (Ranck, 1973; Weiss et al., 1996; Bruno and Simons, 2002). The population was clearly skewed toward neurons with low baseline firing rates (Fig. 3B). A threshold of $15 \mathrm{~Hz}$ was used to discriminate pyramidal neurons from interneurons. Results are reported after eliminating responses from presumptive interneurons.

Pyramidal neurons were separated into those that exhibited a significant stimulus-induced increase in activity (RI neurons) from those that exhibited a significant decrease in activity (RD neurons) according to a Mann-Whitney $U$ test. Less than $10 \%$ of the population exhibited a mixed response; neurons with that profile were included in both groups. Both RI and RD neurons were found at each recording site. Sites were located in different cortical layers of all three subregions. This indicates that there is no obvious regional or layer specificity for these two general classes of neurons.

\section{Analysis of activity by PFC subregions and response type}

PETHs spanning $1 \mathrm{~s}$ before and $2 \mathrm{~s}$ after CS onset were generated for all neurons for both raw (hertz) and normalized data $(z$ scores). Individual histograms of RI and RD response types within a region and belonging to a particular session were averaged to generate population responses. Average population re- sponses for all RI (Fig. 4) and all RD (Fig. 5) neurons are shown in both hertz and $z$-scores across sessions. A three-way ANOVA with region (PL, rACC, cACC) and sessions as factors and intervals (CS vs Trace) as repeated measures revealed a significant interval $\times$ region interaction $\left(F_{(2,1403)}=8.81, p=0.0002\right)$, indicating that the neural activity varied differentially across trial phases and regions. Subsequently, a two-way ANOVA of mean CS or trace interval $z$-score activity was performed for each brain region with group (conditioned vs pseudoconditioned) and session (D1, pre-C, $\mathrm{C}$, and post- $\mathrm{C}$ ) as factors to examine significant changes in the population response among acquisition sessions and between groups. An additional two-way ANOVA that included only the post-C and retention sessions was performed to determine any differences in population activity as a result of the $30 \mathrm{~d}$ hiatus.

\section{PL cortex}

RI neurons

Activity of RI neurons over acquisition sessions for both conditioned and pseudoconditioned groups exhibited a gradual decline in the mean trace interval $z$-scores $\left(F_{(3,347)}=4.2, p<0.01\right.$; Fig. $\left.4 A\right)$. However, neurons from the conditioned group did respond with statistically greater magnitude than neurons from the pseudoconditioned group $\left(F_{(1,347)}=10.67, p=0.001\right)$. Notably, a comparison of trace interval $z$-scores between post- $C$ and retention sessions, when consolidation should be well established, revealed a significant and robust increase in responding from the conditioned group (session $\times$ group interaction, $\left.F_{(1,170)}=7.24, p<0.003\right)$; this was not observed for activity recorded from pseudoconditioned rabbits during CSalone presentations. Subsequent post hoc tests confirmed that neurons from conditioned rabbits had a significant increase in $z$-scores during the trace period of retention sessions compared with post- $\mathrm{C}$ sessions ( 0.64 for post-C vs 1.53 for retention; one-way ANOVA, 
Retention
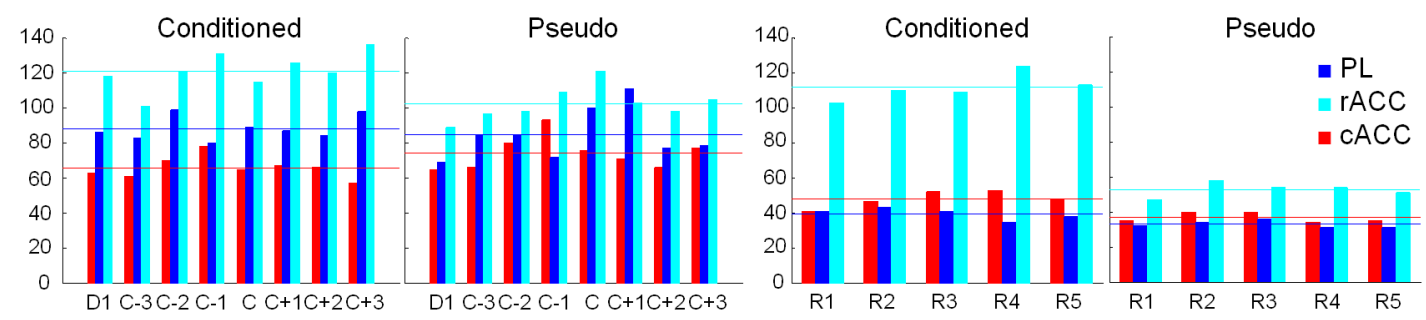

B
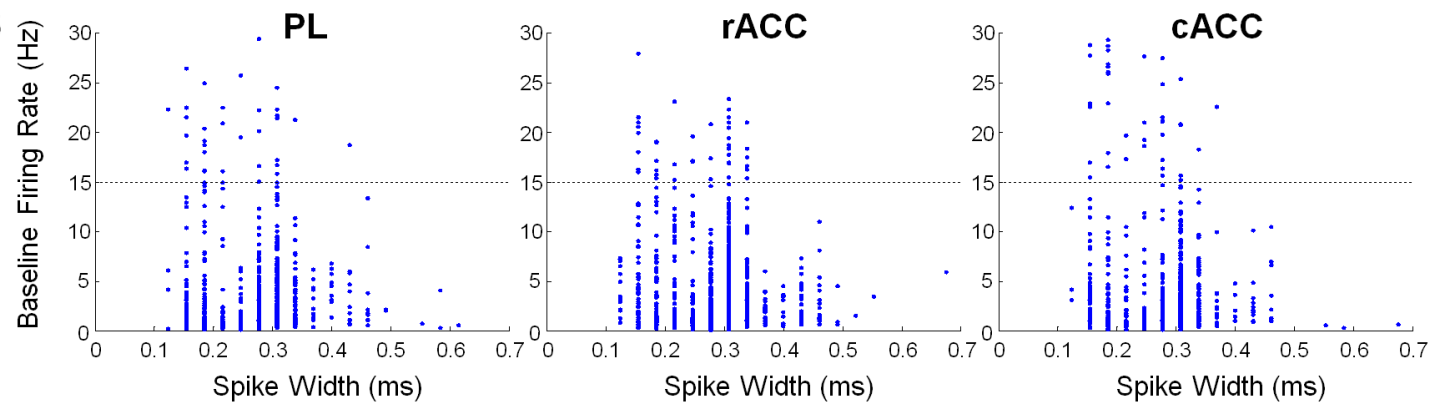

Figure 3. Recorded neurons and classification of cell types. $A$, The total number of neurons recorded per region plotted across days for acquisition and retention sessions for both groups. Red, CACC; blue, PL; cyan, rACC. Horizontal lines represent average number of cells recorded across days for each region in each group. ANOVA revealed no significant effect of sessions and no significant interactions of sessions with group or regions. Note that the acquisition groups included three more rabbits than the retention groups, which accounts for the greater number of neurons recorded during acquisition. B, Clustering within the distribution of spike width and baseline firing rate ( 2 before $C S$ onset) for all neurons recorded from each region that passed our $S / \mathrm{N}$ criteria (see Materials and Methods) was examined to extracellularly classify recorded neurons into cell types (i.e., pyramidal vs interneuron). A baseline firing rate of $15 \mathrm{~Hz}$ was used to separate putative pyramidal neurons from interneurons (dotted horizontal line).

$\left.F_{(1,103)}=16.8, p<0.0001\right)$; the change for neurons from pseudoconditioned rabbits was not significantly different between sessions ( 0.41 for post- $\mathrm{C}$ vs 0.30 for retention). In contrast, activity during the CS interval did not show any significant differences across sessions or between groups. Last, the baseline firing rate across sessions did not change for either group but did increase for both groups during retention sessions relative to the post-C session $\left(F_{(1,170)}=7.75, p=0.006\right)$.

In addition to examining changes in activity of conditioned animals relative to control animals, we further examined within conditioned animals changes in activity specific to the CS and trace intervals across sessions. A significant interval (CS vs trace) $\times$ session interaction was observed during acquisition sessions $\left(F_{(3,196)}=2.61, p=0.05\right)$ in which on D1, trace interval activity was of higher magnitude than the CS interval $(0.54 \pm$ 0.21 for CS vs $1.09 \pm 0.15$ for trace, $\left.F_{(1,26)}=4.438, p=0.04\right)$. However, on subsequent sessions and also during retention sessions, no significant differences were observed between CS and trace interval mean $z$-scores.

\section{$R D$ neurons}

CS and trace interval $z$-score activity of PL RD neurons (Fig. $5 A$ ) did not differ between conditioned and pseudoconditioned groups and did not exhibit changes across days. However, RD neurons of the conditioned group exhibited overall a significantly lower baseline firing rate than neurons from the pseudoconditioned group during acquisition sessions $(2.37 \pm 0.17$ vs $3.00 \pm$ $\left.0.27 \mathrm{~Hz}, F_{(3,423)}=5.97, p=0.01\right)$ and during retention sessions as well $\left(1.83 \pm 0.20\right.$ vs $\left.2.93 \pm 0.43 \mathrm{~Hz}, F_{(1,268)}=6.34, p=0.01\right)$.

\section{cACC}

\section{RI neurons}

Neurons throughout the extent of the cACC of conditioned rabbits exhibited an obvious, stimulus-locked response to the CS and US (Fig. 4C), especially on the first day of training. In general, significant differences in activity between groups and sessions were revealed when comparing the responses during the trace interval but not the CS interval. During acquisition sessions, mean trace interval $z$-scores of both groups exhibited a gradual decline over sessions $\left(F_{(3,265)}=4.85, p=0.003\right)$, but the conditioned group activity had a greater overall magnitude than that of the pseudoconditioned group $\left(F_{(1,265)}=7.39, p=0.007\right)$. Interestingly, a comparison of mean trace interval $z$-score activity during post- $C$ and retention sessions revealed a rebound in activity during retention sessions for both groups combined $\left(F_{(1,156)}=\right.$ $6.37, p=0.01$ ), indicating a re-engagement of the cACC after the 30 day hiatus. Comparisons of activity during the CS interval did not reveal any significant differences.

\section{$R D$ neurons}

Similar to RI neurons, RD neurons (Fig. 5C) did not exhibit significant differences in CS interval activity either between groups or across acquisition sessions. However, decreases during the trace interval were found to be significantly greater for the conditioned than for the pseudoconditioned group for the post- $C$ and retention sessions $(-0.57 \pm 0.03$ vs $-0.41 \pm 0.04$, $\left.F_{(1,335)}=11.17, p<0.001\right)$. In fact, comparison of CS activity to trace activity of conditioned animals indicated a significant interval $\times$ session interaction $\left(F_{(1,198)}=6.03, p=0.01\right)$ in which the magnitude of rate decrease was significantly greater during the trace interval than the CS interval $(-0.35 \pm 0.03$ for CS vs $-0.55 \pm 0.02$ for trace, $\left.F_{(1,199)}=23.67, p<0.0001\right)$.

rACC

\section{RI neurons}

Mean trace interval activity of RI rACC neurons (Fig. 4B) exhibited a gradual decline across acquisition sessions with both groups combined $\left(F_{(3,454)}=2.71, p=0.045\right)$; there was no difference between groups and no interaction of group and session. During retention sessions, there was a generalized significant increase in activity from post- $C$ to retention sessions $\left(F_{(1,378)}=\right.$ 


\section{Rate Increasing Neurons}
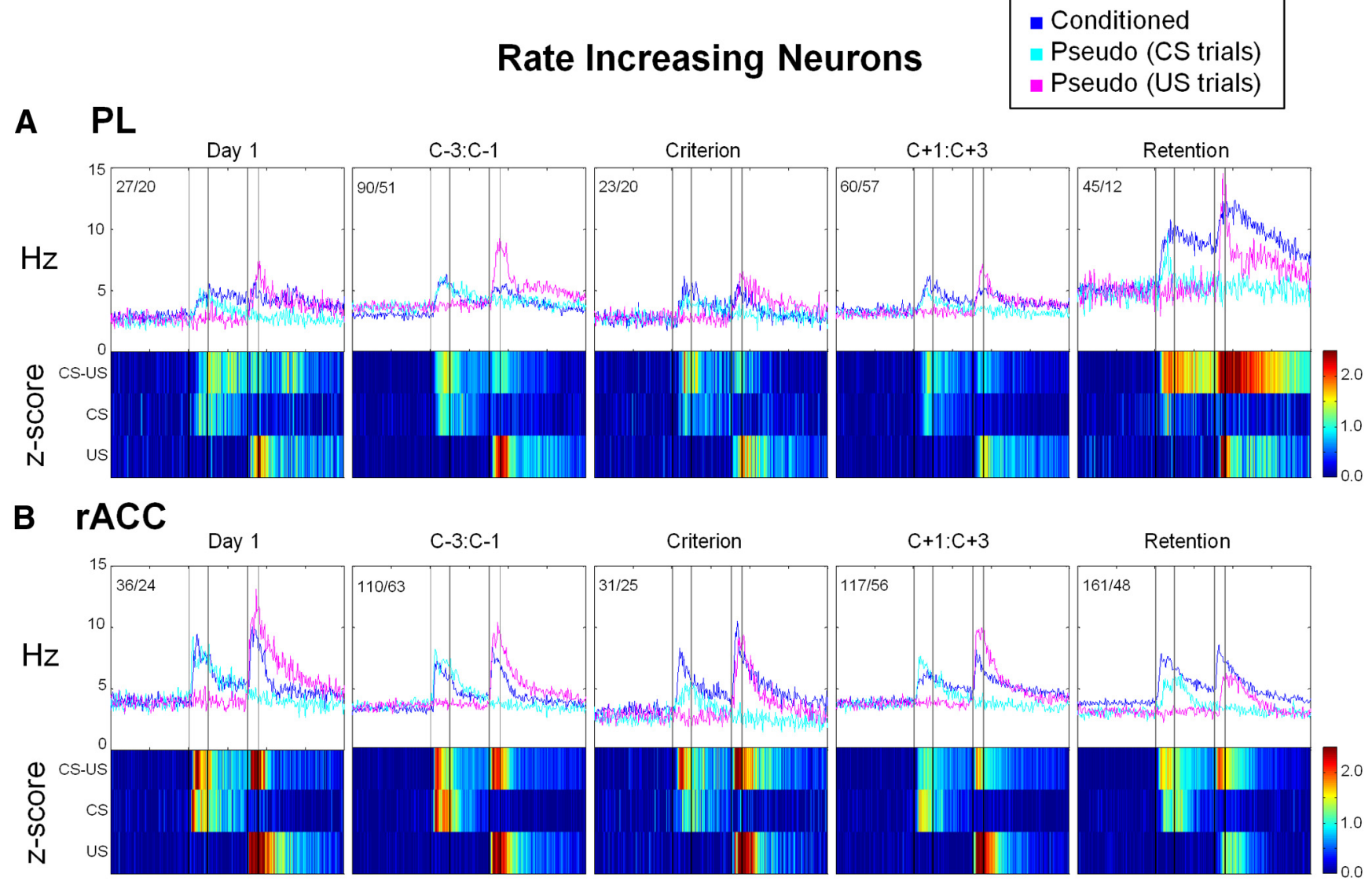

C-3:C-1
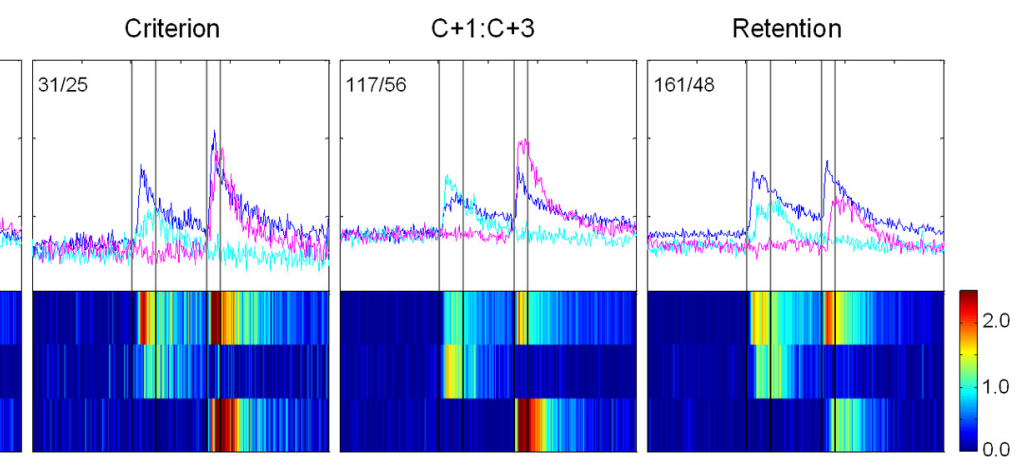

\section{CACC}
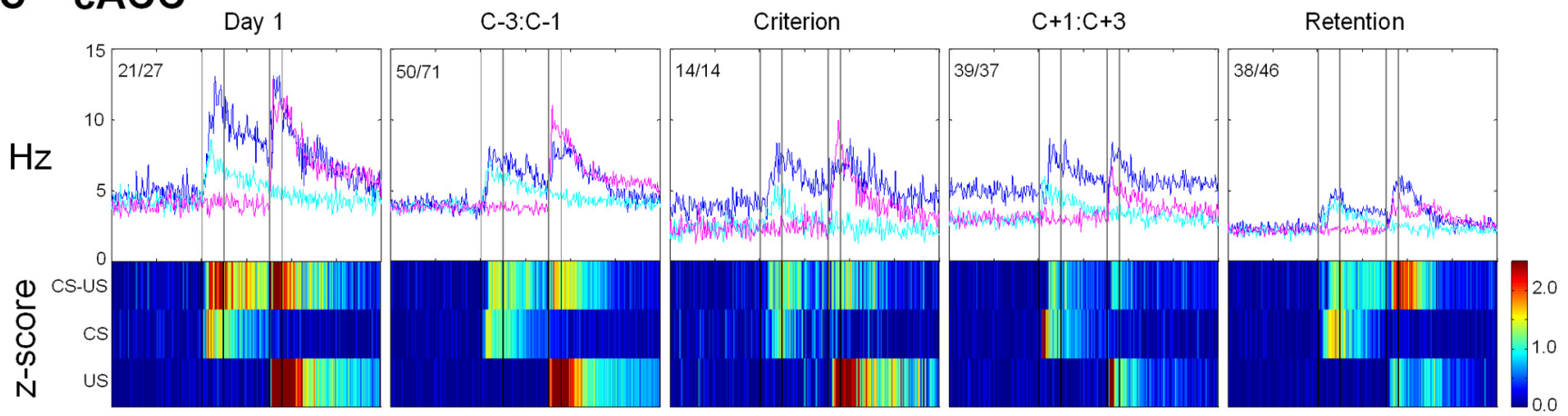

Figure 4. Activity of RI neurons differs across sessions and among regions. $A, P L ; B, r A C C ; C, C A C C$. Top panels of each section show PETHs of neuronal activity (hertz) for the population of neurons for the first day of training, the average of the three sessions before the criterion session $(C-3: C-1)$, the criterion session, the average of the three sessions after the criterion session $(C+1: C+3)$, and the average of five sessions to test retention at a point $30 \mathrm{~d}$ after the end of acquisition training. Bottom panels show the population data as $z$-scores normalized to the baseline period. Values are color coded to indicate the magnitude of the $z$-score. Vertical lines indicate $C S$ and US intervals. Values at top left of each rate histogram show number of RI neurons for the two groups (Conditioned, Pseudo).

$5.48, p=0.020$ ), and neurons from the conditioned group exhibited an overall greater magnitude of response than those from the pseudoconditioned group $\left(F_{(1,378)}=5.13, p=0.024\right)$; there was no significant interaction of group and session. In comparison, CS interval activity did not exhibit any significant differences during acquisition sessions. However, during retention sessions, a significant group $\times$ session interaction was observed $\left(F_{(1,378)}=\right.$ $4.6, p=0.033$ ), and follow-up ANOVA confirmed that the activity of neurons from the conditioned group increased from post-C to retention sessions $\left(0.877 \pm 0.138\right.$ vs $1.27 \pm 0.127, F_{(1,276)}=$ 4.327, $p=0.038$ ), whereas the activity of neurons from the pseudoconditioned group exhibited a decrease in responsivity during the CS period.
In conditioned animals, comparison of mean $z$-scores during the CS and trace intervals revealed a significant interval effect during both acquisition $\left(F_{(1,196)}=8.23, p=0.0046\right)$ and retention sessions $\left(F_{(1,198)}=12.79, p=0.0004\right)$. Subsequent ANOVAs confirmed that, at both time points, CS interval activity was of much greater amplitude than that during the trace interval (acquisition: $1.33 \pm 0.14$ for CS vs $0.76 \pm 0.06$ for trace, $F_{(1,199)}=$ $15.12, p=0.0001$; retention: $1.18 \pm 0.12$ for CS vs $0.76 \pm 0.05$ for trace, $\left.F_{(1,199)}=11.11, p=0.001\right)$, suggesting stimulus-specific responses of rACC neurons.

Previous examinations of the rACC have led to the suggestion that the rACC is involved in error detection, conflict monitoring, attention, or evaluative mechanisms that monitor emotional sa- 


\section{Rate Decreasing Neurons}

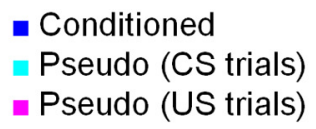

- Conditioned

- Pseudo (US trials)

A PL

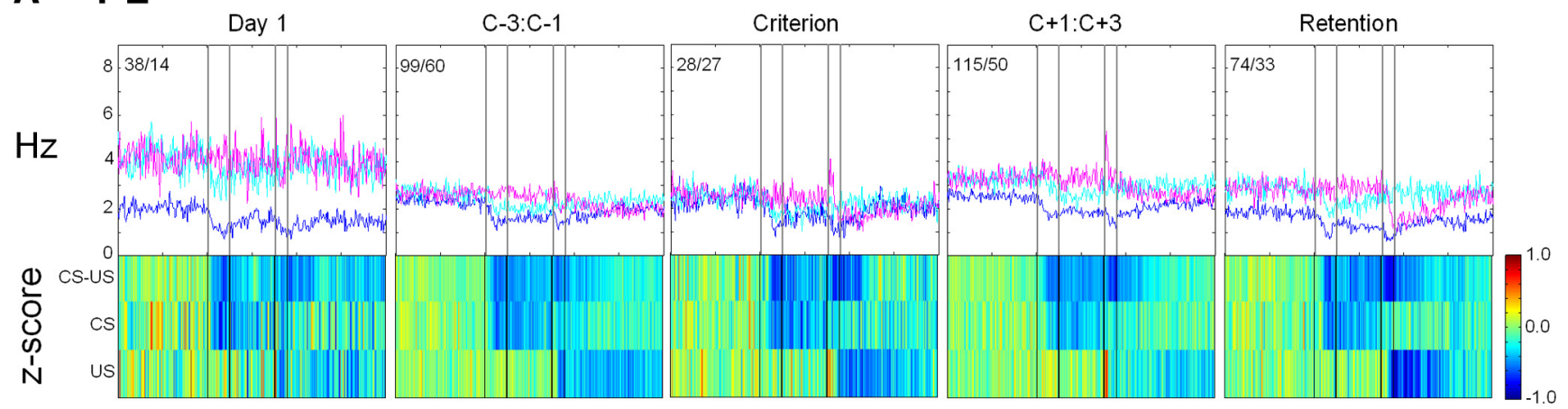

B $\mathrm{rACC}$

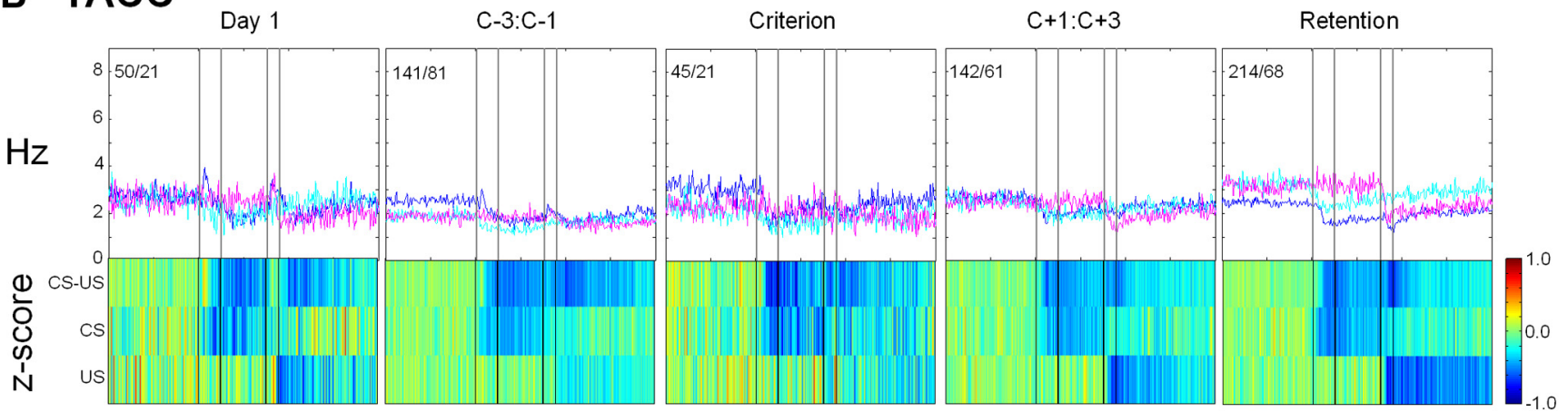

\section{C $\mathrm{CACC}$}
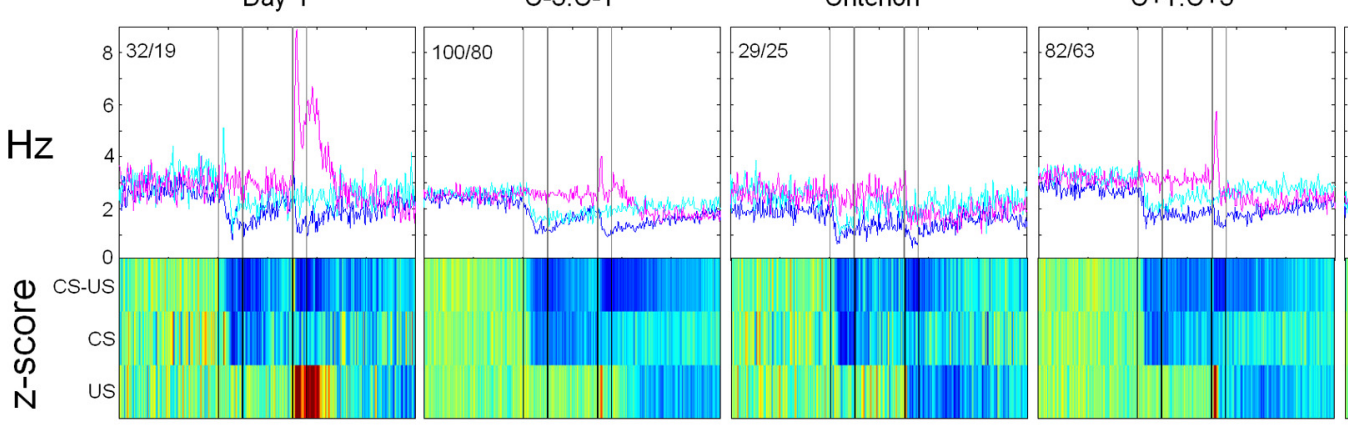

Retention

Figure 5. Activity of RD neurons differs across sessions and among regions. A, Prelimbic cortex (PL). B, Rostral anterior cingulate cortex (rACC). C, Caudal anterior cingulate cortex (CACC). For more detail, see legend to Figure 4.

lience of stimuli (Totah et al., 2009). To determine whether this premise is evident based on the history of trials, we plotted the mean firing rate of RI neurons during the CS-trace interval for all trials of all sessions. Results from conditioned animals (Fig. 6A) indicate that RI rACC neurons exhibited a decrease in firing rate across trials within each session. For each session, a linear regression was performed to highlight this decrease in activity. A plot of the linear regression slopes across all sessions shows consistently negative slopes for the conditioned group. In contrast, RI rACC neurons from pseudoconditioned rabbits show negative slopes for the first three sessions, but thereafter, the remaining slopes appear to be variable in terms of direction (positive/negative). These results appear to be unique to the rACC subregion (Fig. 6) and suggest that the rACC is involved in evaluating the emotional salience of stimuli (Phan et al., 2003). Although the mean firing rate of RI PL neurons from pseudoconditioned rabbits also ap- pears to decrease within each retention testing session (Fig. 6C), that result is based on the population with the fewest number of neurons (one to four neurons per session; Fig. 4B, PL) and neurons that were much less likely to exhibit a persistent change in firing rate (Fig. 7, R1:R5). Thus, the variability in CS-trace interval responding during retention sessions accounts for a poor fit to the linear model as measured by the root mean square error (RMSE) of the linear regression, i.e., the RMSE during retention sessions is greater than during acquisition sessions $(2.61 \pm 0.35$ vs $0.91 \pm 0.07$, mean \pm $\mathrm{SEM}$ ). As such, the resultant slopes for the retention sessions may be spurious when analyzing the data on a trial-by-trial basis as opposed to analyzing the session mean for each animal.

\section{$R D$ neurons}

Comparisons of CS interval activity of RD rACC neurons (Fig. $5 B$ ) did not reveal any significant differences between groups or 


\section{A raCC Rate-Increasing}
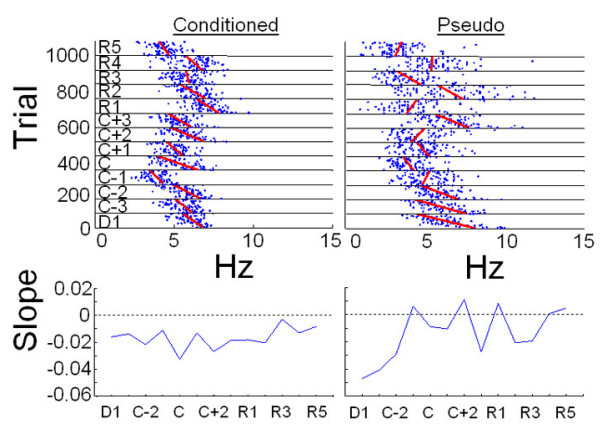

D racc Rate-Decreasing
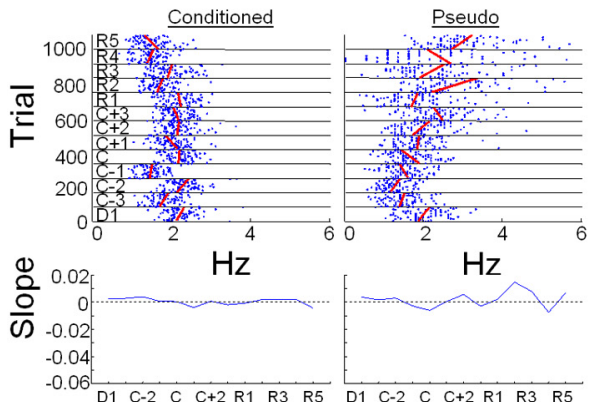

B $\underline{\text { cACC Rate-Increasing }}$
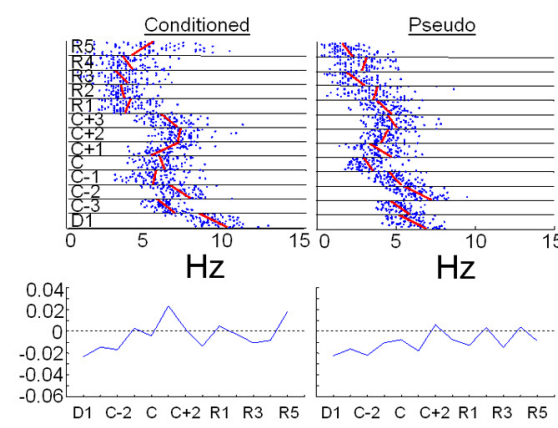

\section{PL Rate-Increasing}

\section{$F$}
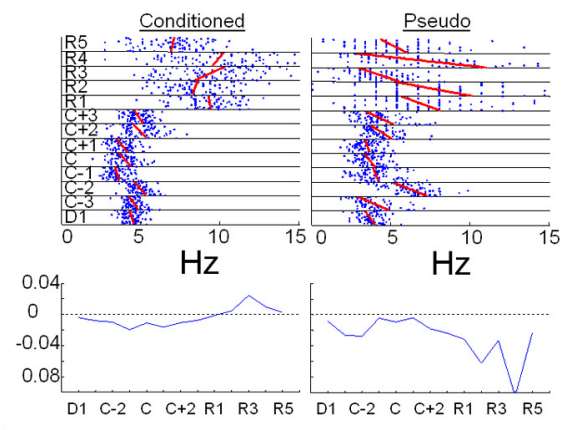

E cACC Rate-Decreasing
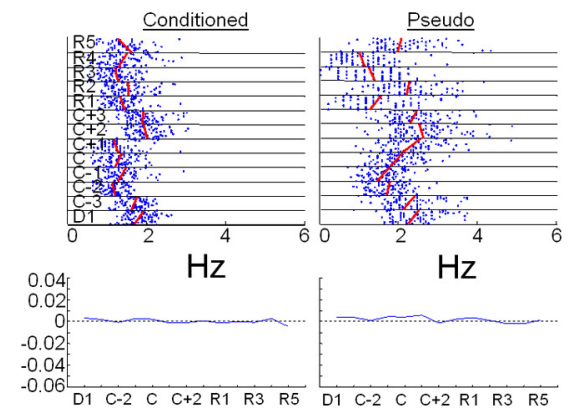

\section{PL Rate-Decreasing}

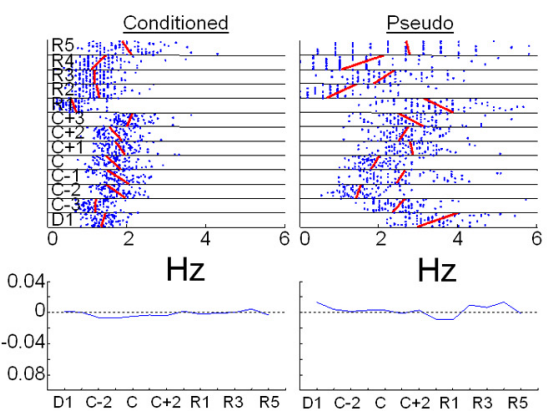

Figure 6. $\quad \mathrm{rACC}$ neurons exhibit within-session decreases in responsivity to stimuli. Mean CS-trace interval firing rate in hertz ( $X$-axis) of RI $(\boldsymbol{A}-\boldsymbol{C})$ and RD $(\boldsymbol{D}-\boldsymbol{F})$ neurons from the rACC $(\boldsymbol{A}, \boldsymbol{D})$, $\mathrm{CACC}$ $(\boldsymbol{B}, \boldsymbol{E})$, and $\mathrm{PL}(\boldsymbol{C}, \boldsymbol{F})$ of conditioned and pseudoconditioned rabbits plotted over all trials ( $y$-axis) from first day of acquisition (D1; bottom) through last day of retention testing (R5; top). Horizontal black lines separate individual training sessions during acquisition and retention (80 trials per session). The red lines denote linear regression of firing rates of all trials within each session, demonstrating the change in firing rate from early trials to later trials within the session. Below each raster type display is a graph plotting the slope of the linear regression fits across training sessions. Note the consistently negative slopes (a shift from high to low firing rates within each session) for data from the rACC of conditioned rabbits as opposed to data from pseudoconditioned rabbits and other brain regions.

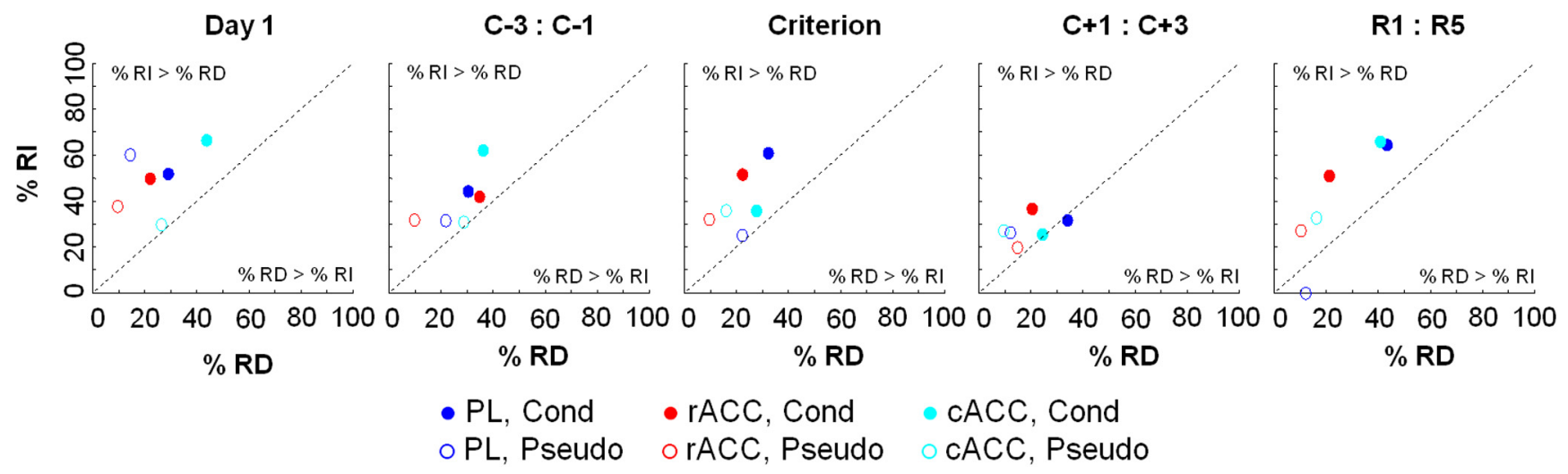

Figure 7. Percentage of persistently responsive neurons is greater for conditioned than pseudoconditioned rabbits. The percentage of persistently responsive RI neurons are plotted against the percentage of persistently responsive RD neurons for day 1 , the three pre-criterion sessions $(C-3: C-1)$, the criterion session $(C)$, the three post-criterion sessions $(C+1: C+3)$, and the five retention sessions (R1:R5). Data are separated by region (blue, PL; red, rACC; cyan, CACC) and group (filled circles, conditioned; open circles, pseudoconditioned) according to color and symbols. Diagonal line represents unity, i.e., an equal percentage of persistently responsive RI and RD neurons. Notice that, in most cases, persistently responsive RI neurons are more frequent than persistently responsive $\mathrm{RD}$ neurons, and conditioned rabbits exhibit more persistently responsive neurons than pseudoconditioned control rabbits.

among acquisition sessions. However, activity during the trace interval revealed a significant group difference during acquisition sessions $\left(F_{(1,554)}=4.2, p=0.04\right)$, with neurons of the conditioned group exhibiting larger magnitude rate decreases than neurons from the pseudoconditioned group. No such trend was apparent for the transition from post- $\mathrm{C}$ to retention sessions. Within conditioned rabbits, trace interval activity exhibited a significantly larger magnitude of rate decrease than the CS interval $\left(-0.25 \pm 0.06\right.$ for CS vs $-0.51 \pm 0.02$ for trace, $F_{(1,199)}=$ 15.76, $p=0.0001)$ during acquisition sessions but not during retention sessions.

\section{Changes in activity across PFC subregions}

A three-way ANOVA comparing trace interval $z$-score activity for interactions of session (D1, pre-C, C, post-C, retention), group (conditioned vs pseudoconditioned), and brain region (PL, rACC, cACC) was used to determine differences among subregions across sessions. Results indicated a three-way interaction that approached statistical significance for RI neurons $\left(F_{(8,1403)}=\right.$ $1.82, p=0.06)$. This is seen clearly in Figure 4 where there is noticeable RI activity in the cACC during early acquisition periods that shifts to the PL during retention sessions. Subsequent ANOVAs revealed that this three-way interaction is driven by 
neuronal activity in the conditioned group, which demonstrated a significant session $\times$ region interaction $\left(F_{(8,847)}=3.0, p=\right.$ $0.003)$, whereas neuronal activity obtained from CS-only trials of the pseudoconditioned group did not. Only the PL $\left(F_{(4,240)}=\right.$ $8.10, p<0.0001)$ and $\operatorname{cACC}\left(F_{(4,157)}=3.56, p<0.01\right)$ regions were found to change across sessions during conditioning. ANOVAs conducted separately for each time point revealed that the three regions exhibited significant differences in activity especially during retention sessions (one-way ANOVA, $F_{(2,347)}=$ $6.32, p=0.002$ ) in which PL activity was significantly different from cACC activity ( $p o s t$ hoc Fisher's PLSD test, $p=0.0033$ ) and rACC activity ( $p o s t$ hoc Fisher's PLSD test, $p=0.0006$ ). These changes are evidence of the functional reorganization of neuronal activity that occurs in the PFC as memory is stored.

Conversely, RD activity did not exhibit a significant three-way interaction among group, session, and brain region. However, an overall group difference was observed $\left(F_{(1,1976)}=7.76, p=\right.$ 0.005 ), with neurons from the conditioned group having greater negative $z$-scores compared with neurons from the pseudoconditioned group (post hoc Fisher's PLSD, -0.46 vs $-0.40, p<$ 0.001).

To examine changes in activity relative to distinct events within the trial, we further performed within conditioned animals an interval $\times$ region $\times$ session three-way ANOVA with CS and trace intervals as repeated measures. Results revealed that, for RI neurons, activity between the CS and trace intervals significantly differed among regions during both acquisition $\left(F_{(2,606)}=\right.$ $6.50, p=0.001)$ and retention $\left(F_{(1,454)}=4.17, p=0.01\right)$ sessions. Specifically, activity of RI rACC neurons during the CS interval was significantly greater than activity during the trace interval during both acquisition and retention (acquisition: $1.34 \pm 0.15$ for CS vs $0.76 \pm 0.06$ for trace, $F_{(1,199)}=15.12, p=0.0001$; retention: $1.18 \pm 0.12$ for CS vs $0.76 \pm 0.05$ for trace, $F_{(1,199)}=$ $11.11, p=0.001)$. These results suggest that RI rACC activity is specific to the CS interval as evident in the population histogram in Figure 4B. In comparison, other regions (PL and CACC) did not exhibit this trend, suggesting that CS-driven responses generally continue into the trace interval.

For RD neurons, a significant interval $\times$ region $\times$ session interaction was observed for acquisition sessions $\left(F_{(6,889)}=2.22\right.$, $p=0.04)$, indicating that the activity differed between the intervals among regions and over learning. Specifically, ANOVAs revealed interval $\times$ region interactions on $\mathrm{D} 1\left(F_{(2,117)}=3.28, p=\right.$ $0.04)$ and pre-C $\left(F_{(2,337)}=4.18, p=0.02\right)$ in which rACC neurons exhibited a greater magnitude of rate decrease during the trace interval than the CS interval (D1: $-0.16 \pm 0.14$ for CS vs $-0.50 \pm 0.04$ for trace, $p=0.026$; pre-C: $-0.27 \pm 0.07$ for CS vs $-0.50 \pm 0.03$ for trace, $p=0.003)$. CS and trace interval RD neuron activity did not differ significantly on $\mathrm{C}$ and post-C sessions. During retention sessions, a significant interval $\times$ region interaction $\left(F_{(2,766)}=3.35, p=0.03\right)$ and interval $\times$ session interaction $\left(F_{(1,766)}=3.78, p=0.05\right)$ was observed but no interaction. Overall, the trace interval exhibited a greater magnitude of rate decrease than the CS interval $(-0.35 \pm 0.03$ for CS vs $-0.55 \pm 0.02$ for trace, $\left.F_{(1,226)}=27.438, p<0.0001\right)$ in which the difference was driven primarily by cACC activity $\left(F_{(1,226)}=\right.$ 27.438, $p<0.0001$ ).

We further examined differences in the latency of responses of each neuron among the subregions relative to CS onset. After binning the activity of each neuron at $1 \mathrm{~ms}$ resolution, onset latencies were determined using a method inspired by Kiani et al. (2005) (see Materials and Methods). Results indicated that onset times of RI neurons differed significantly among the regions dur- ing acquisition sessions $\left(F_{(2,625)}=3.25, p=0.04\right)$, with cACC neurons exhibiting earlier onset latencies relative to those of the PL and rACC neurons. Specifically, cACC neurons preceded PL activity by $64 \mathrm{~ms}$ (cACC, $180.74 \pm 13.83 \mathrm{~ms}$; PL, $245.41 \pm 17.82$ $\mathrm{ms}, p=0.017$ ) and preceded rACC activity by $54 \mathrm{~ms}$ (rACC, $234.63 \pm 14.65 \mathrm{~ms}, p=0.035$ ). In contrast, onset latencies among the three regions did not differ significantly during retention sessions (cACC, $208.13 \pm 19.59 \mathrm{~ms} ; \mathrm{PL}, 230.66 \pm 24.62 \mathrm{~ms}$; rACC, $228.43 \pm 15.88 \mathrm{~ms}$ ). Similarly, onset latencies of RD neurons were not significantly different during acquisition (cACC, $25.18 \pm 1.92 \mathrm{~ms} ; \mathrm{PL}, 28.85 \pm 2.52 \mathrm{~ms}$; rACC, $31.57 \pm 2.28 \mathrm{~ms}$ ) or retention (cACC, $36.14 \pm 2.98 \mathrm{~ms}$; PL, $29.52 \pm 2.74 \mathrm{~ms}$; rACC, $31.72 \pm 2.08 \mathrm{~ms}$ ) sessions but were generally much earlier than RI neurons.

\section{Persistent responses span the stimulus-free trace interval}

We examined neurons for a significant stimulus-induced persistent response during the stimulus-free trace interval. We used continuous SDFs to minimize artifacts for spikes that occur near the edge of a time bin (Richmond et al., 1987; Szucs, 1998). Neurons with persistent activity were operationally defined as those with activity that exceeded the mean baseline period SDF by 2.575 SDs $(p=0.01)$ for a minimum of $70 \%$ of the $500 \mathrm{~ms}$ trace interval, i.e., $\geq 350 \mathrm{~ms}$. Figure 7 shows plots of the percentage of $\mathrm{RI}$ and RD neurons that are persistently responsive for each of the three subregions. Note that neurons from conditioned rabbits exhibit a greater percentage of persistent neurons than the percentage observed from pseudoconditioned rabbits for most regions during most sessions and that the majority of points are above the line of unity, which indicates that the percentage of persistently responsive RI neurons is greater than the percentage of persistently responsive RD neurons, although both cell types were observed. On day 1, both conditioned and pseudoconditioned groups exhibited persistent responses, suggesting an innate responsiveness to the CS. During retention testing (R1-R5), the difference in persistent activity between conditioned and control rabbits becomes more robust in all three PFC regions. These results indicate that memory for the CS-US association during remote retention is associated with persistent responses that span the stimulus-free trace interval and act to express the CR.

\section{CR vs no-CR trials}

If neurons in a region of the PFC are driving expression of CRs, there should be a reflection of that activity during CR trials and not during trials in which no CRs were elicited (no-CR trials). As shown in Figure 8, all three PFC subregions exhibited a greater magnitude of change during no-CR trials during sessions before criterion (D1, C-3:C-1), i.e., a greater increase for RI neurons and greater decrease for $\mathrm{RD}$ neurons. This pattern reversed after the day of criterion, showing a greater change in activity during CR trials than no-CR trials in post-criterion sessions. This trend was of even greater magnitude at the $30 \mathrm{~d}$ retention test [mixeddesign ANOVA with trial type $(\mathrm{CR} / \mathrm{no}-\mathrm{CR})$ as a repeated measure and session as factors; RI PL: $F_{(4,240)}=52.72, p<0.001$; RI rACC: $F_{(4,450)}=42.53, p<0.001 ;$ RI cACC: $F_{(4,157)}=17.04, p<0.001$; RD PL: $F_{(4,240)}=50.26, p<0.001$; RD rACC: $F_{(4,450)}=76.08, p<$ 0.001 ; RD cACC: $\left.F_{(4,383)}=64.45, p<0.001\right]$. These results, combined with the observation that neuronal recruitment does not appear to change across sessions (see below, Changes in neuronal recruitment; Fig. 9), suggests that the mPFC likely codes learning and memory through rate modulation of innately responsive neurons rather than by the recruitment of neurons that were previously unresponsive. 


\section{A Rate-Increasing Neurons}

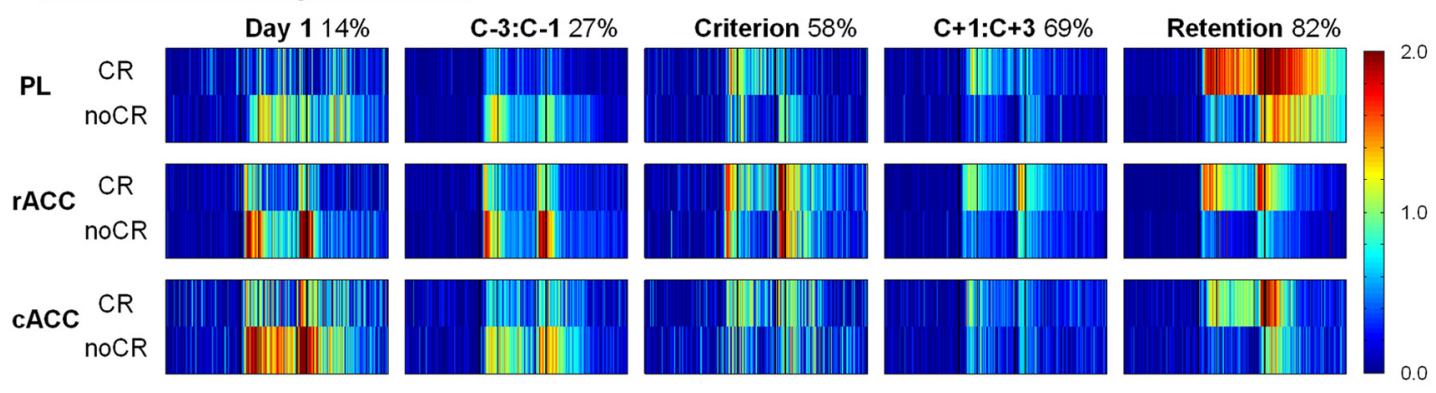

B
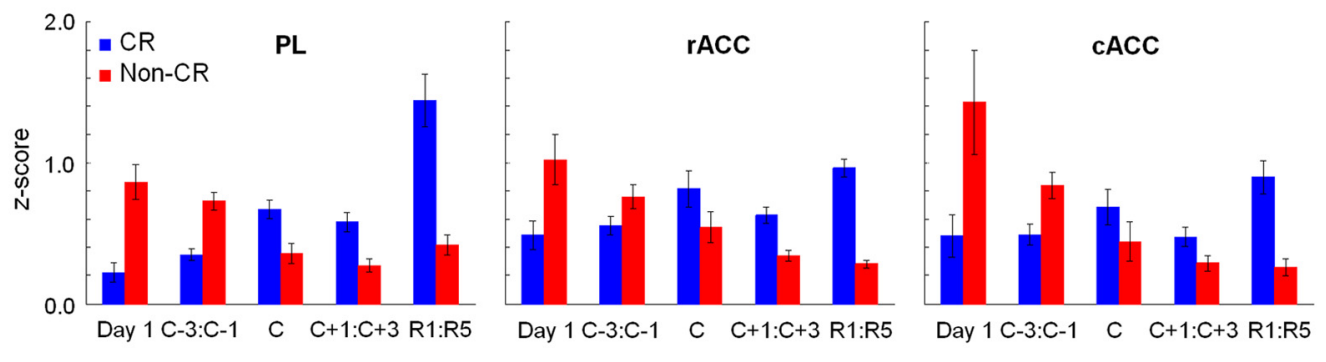

C Rate-Decreasing Neurons

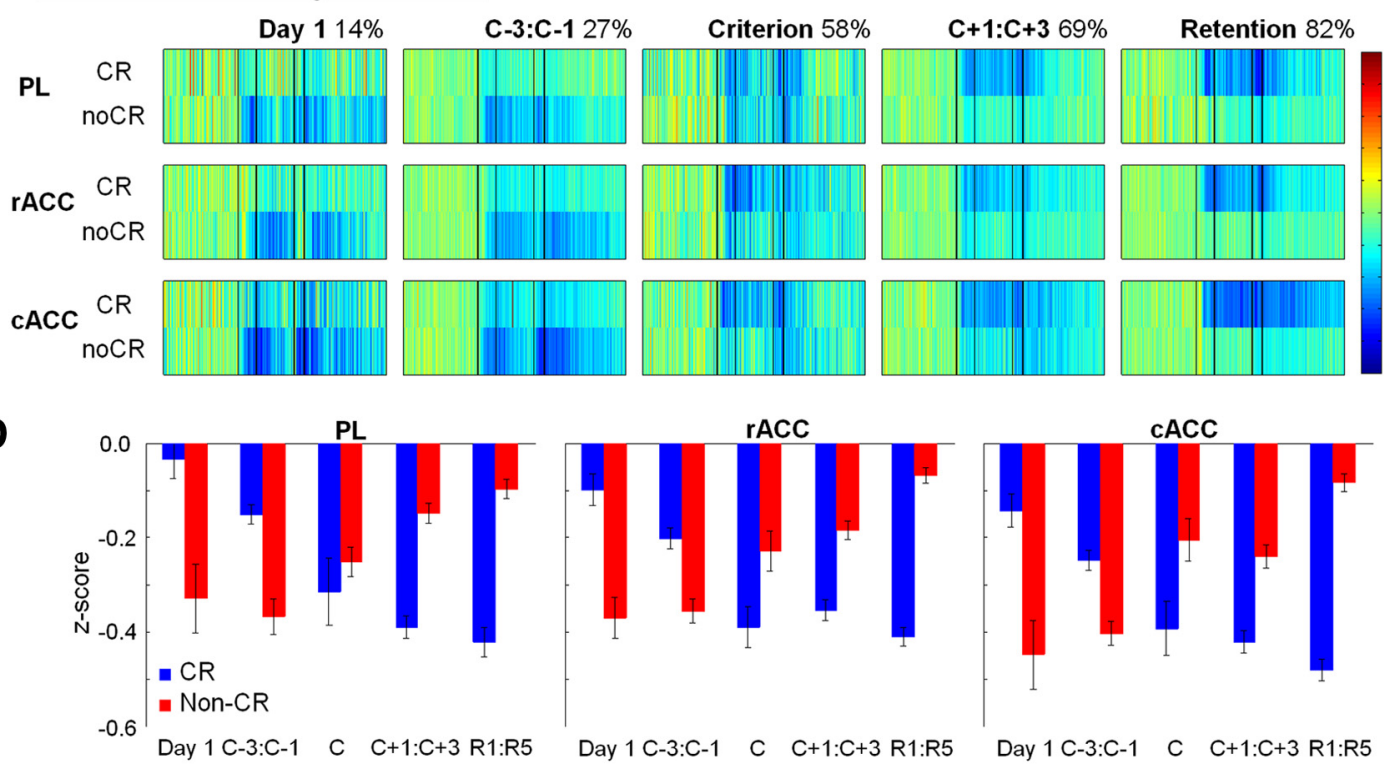

Figure 8. Neuronal activity is significantly different between $C R$ and non-CR trials. PETHs of $z$-scores expressed in pseudocolor $(A, C)$ and the mean $z$-score during the $C S$-trace interval across sessions $(\boldsymbol{B}, \boldsymbol{D})$ after separating the data into trials with $(C R)$ or without (no-CR) a conditioned response for each of the three PFC subregions. Note that both Rl and RD neurons are more responsive during no-CR trials of pre-criterion sessions and during $C R$ trials of post-criterion sessions.

\section{Changes in neuronal recruitment}

In addition to rate modulation, plasticity can also be encoded by changes in the number of responsive neurons (although this can also be considered a change in rate modulation from subthreshold to suprathreshold activation). The percentage of responsive neurons was compared between conditioned and pseudoconditioned rabbits for individual training sessions using $\chi^{2}$ analyses (Fig. 9). Overall, the percentage was greater for conditioned than for pseudoconditioned rabbits (69 vs 46\%), and the difference between the two groups was larger for RD neurons ( $42 \%$ for conditioned vs $25 \%$ for pseudoconditioned) than for RI neurons ( $27 \%$ for conditioned vs $21 \%$ for pseudoconditioned), especially in the rACC (39 vs $23 \%$ ) and cACC (51 vs $30 \%$ ). Note that, although the conditioned group exhibits more responsive neurons than the pseudoconditioned group, there is relatively little change in the percentage of responsive neurons from the first day of training through the last day of retention testing. This suggests that the PFC codes learning by rate modulation of innately responsive neurons rather than by the recruitment of neurons that were previously unresponsive.

\section{Discussion}

The present study aimed to characterize how neuronal activity within three subregions of the rabbit mPFC changes over time as an associative memory is formed, consolidated, and remotely retrieved. The present results provide electrophysiological support for a longitudinal, subregional functional segregation and reorganization of the rACC, CACC, and PL network during mnemonic processes. We propose, based on review of existing literature and results of the current study, that depending on the cognitive require- 
ments to complete the task, the mPFC as a whole is flexible and involved in attention, stimulus valuation, and expression of behavior evoked by remotely acquired memories (Fig. 10).

Compared with acquisition sessions, a striking increase in neuronal activity was observed in the PL during remote trace $\mathrm{EBC}$ retention of conditioned animals but not of control animals (Fig. 4A). Furthermore, the activity started during the CS period and persisted throughout the stimulus-free trace period for conditioned animals but not control animals (Fig. 7), thus indicating that the persistent response is specific to learning rather than mere exposure to the CS. These results suggest that the CS-US association is gradually conferred to the PL such that the PL mediates the retrieval/expression of remotely acquired memories as learning progresses and is consolidated (Fig. 10). A similar trend was reported previously in contextual trace EBC (TakeharaNishiuchi and McNaughton, 2008), although we show that the responsivity is exhibited by putative pyramidal neurons. Lesion studies also support this view because studies have shown transient impairments in remote trace EBC memory recall but not in acquisition after selective damage to the PL (Oswald et al., 2008, 2009, 2010). Fear conditioning studies have also suggested a role for the PL in remote storage/ expression of learned fears but not acquisition of fear responses (Runyan et al., 2004; Corcoran and Quirk, 2007; Quinn et al., 2008; Choi et al., 2010). Thus, the response patterns we report in the PL supports the idea that the PL mediates retrieval/expression of remotely acquired associations.

The large responses observed in cACC during early sessions of trace EBC acquisition, but not during tests of remote retention, suggest that the $\mathrm{CACC}$ mediates an attentional role to enable the formation of a CS-US association by encoding behaviorally relevant stimuli (Ng et al., 2007), perhaps with feedback from the cerebellum (Weiss and Disterhoft, 1996, 2011; Weiss et al., 2006; Siegel and Mauk, 2013). This view is consistent with cACC lesion studies that have demonstrated impaired trace EBC acquisition (Weible et al., 2007). Furthermore, the activity of RI cACC neurons we report is similar to those reported by Weible et al. (2003) in that cACC activity decreased across trace EBC acquisition sessions. However, that study did not examine activity after consolidation, so our results, obtained longitudinally during recent and remote time points, revealed that the decrease in activity stabilizes by the day of criterion and CACC activity rebounds in responsiveness during retention testing. These results suggest that the cACC shows an innate responsiveness to novel stimuli that decreases if there is no behavioral significance as in the case of pseudoconditioned trials and a reactivation when the significance of the stimuli needs to be reinstantiated. The spatial distribution and responsivity of persistently firing neurons in cACC was similar to that reported by Siegel et al. (2012), although they did not evaluate such activity during pseudoconditioning, or after a conditioning-free hiatus to examine the effects of consolidation.

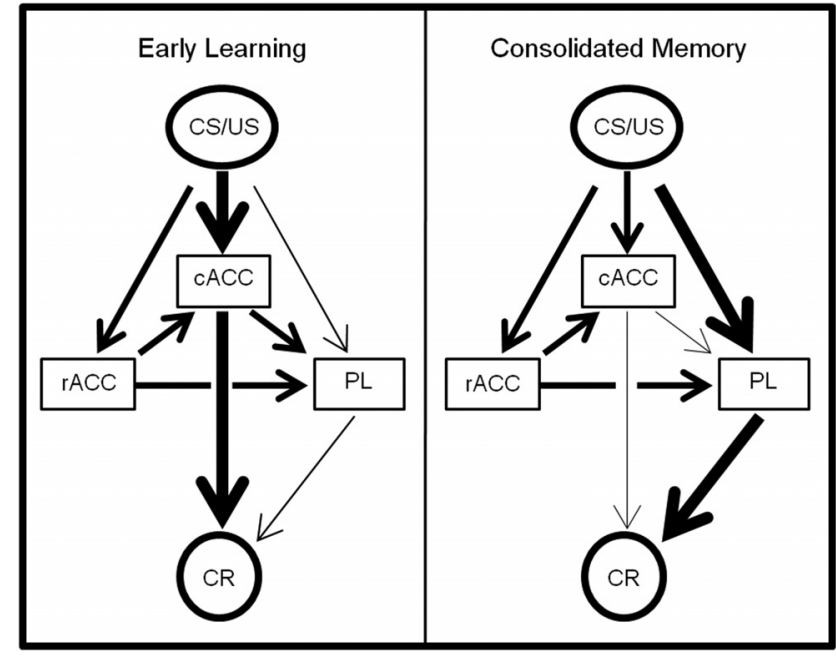

Figure 10. Proposed functional connectivity among $\mathrm{mPFC}$ subregions during acquisition and consolidation of $\mathrm{CRs}$. During acquisition of $\mathrm{EBC}$, the $\mathrm{CACC}$ may mediate an attentional role to enable the formation of a CS-US association. Thus, connectivity among regions involved in the association of the CS and US and the areas involved in the production of CRs would become strengthened (bold lines). As learning progresses and consolidates, the CS-US association may gradually be conferred to the PL cortex such that, during remote memory recall, the PL cortex mediates expression of remotely acquired CRs. The CACC and PL together may form a cognitive component of the $\mathrm{mPFC}$ that enables the formation and consolidation of the CS-US association. In contrast, the rACC, given its phasic changes in activity during each session (Fig. 4), may form an affective component of the mPFC that evaluates the emotional salience of incoming stimuli and modulates the activity of the other regions. Arrows do not necessarily represent monosynaptic connections.

Animal studies using other paradigms have also reported that cACC lesions affect the early stages of learning, i.e., animals take longer to achieve above-chance performance levels but eventually do achieve similar levels of accuracy as controls (Gabriel, 1990; Bussey et al., 1996). In addition, various human studies 
have demonstrated cACC involvement in the modulation of attention or stimulus selection (Bush et al., 1998, 1999; Posner and DiGirolamo, 1998; Carter et al., 1999). In fact, some argue, based on human and animal cytoarchitectural, lesion, and electrophysiological studies, that the ACC comprises two major subdivisions that serve distinct functions: the rostral "affective division" and the caudal "cognitive division" (Vogt et al., 1992; Devinsky et al., 1995; Bush et al., 2000). Anatomically, the caudal cognitive division maintains reciprocal connections with the lateral prefrontal, parietal, premotor, and supplementary motor cortices (Devinsky et al., 1995), areas all thought to subserve higher-order, cognitive control. Therefore, the cACC is a prime candidate for modulating attentional mechanisms.

Although our results, in conjunction with empirical literature, make a strong case for an attentional role for the cACC, other functions have been ascribed for the cACC, including error detection, working memory, response selection, complex motor control, motivation, and conflict monitoring (Gemba et al., 1986; Picard and Strick, 1996; Drevets and Raichle, 1998; Posner and DiGirolamo, 1998; Carter et al., 1999). In fact, some studies even suggest that the ACC acts as a memory "storage site" and is preferentially involved in the expression of remote contextual fear and spatial memory (Frankland et al., 2004; Maviel et al., 2004; Teixeira et al., 2006; Weible et al., 2012). However, it can be argued that remote memory expression is accompanied by attentional processing because it has been reported that awareness or knowledge of stimulus contingencies may be an important contributor to mnemonic processes (Clark and Squire, 1998; Knuttinen et al., 2001; Manns et al., 2001). For example, an in vivo recording study for spatial object memory demonstrated that some cACC neurons respond to locations where an object was encountered previously 1 month ago and that animals preferentially explored the location of the absent object (Weible et al., 2012). Although these results certainly indicate long-term memory for object locations, it could also be accompanied by the animal actively searching for and attending to the area to find the missing object. Similarly, remote memory retrieval in other paradigms, such as fear conditioning, requires animals to attend to cues that initiate the expression of remotely acquired memories (e.g., tone or context). Such behavior would manifest in the neural activity of brain regions involved in attentional processing. Thus, dissociating between these functions is difficult, and additional studies are required to fully elucidate the role(s) of the cACC. However, what is common to all the proposed functions of the cACC is that each is contingent on a cognitively demanding task. It has been shown, at least in trace EBC, that the use of different US stimuli can alter the cognitive demand placed on the mPFC. In particular, airpuff US places a greater cognitive demand than periorbital shock US (Oswald et al., 2009). Thus, although our experimental aim was not to explore every proposed function of the cACC per se, by use of airpuff US to place maximal demands on the $\mathrm{MPFC}$, our results nonetheless underscore the importance of the cACC in the formation of CS-US associations in a cognitively demanding associative memory task.

Unlike the other subregions, rACC neurons of conditioned rabbits exhibited phasic decreases in activity during each session, whereas rACC neurons of pseudoconditioned rabbits did not. This pattern of activity may reflect habituation to the stimuli and code the emotional salience of the CS within each training session, i.e., the paired stimuli are less novel and aversive with each successive presentation. This view is consistent with literature that contend that the rostral affective division (Vogt et al., 1992;
Devinsky et al., 1995; Bush et al., 2000) of the ACC is involved in the evaluation of emotional salience in concert with limbic areas, such as the amygdala, nucleus accumbens, hypothalamus, anterior insula, and orbitofrontal cortex (Devinsky et al., 1995; Whalen et al., 1998; Bush et al., 2000; Phan et al., 2002, 2003). For example, human fMRI studies have shown consistent rACC activation in affect-related tasks (Whalen et al., 1998; Bush et al., 2000) and even habituation effects to affective stimuli (Phan et al., 2003), a trend very much similar to the ones we report. Cytoarchitectural and connection studies have further demonstrated that the rACC projects to autonomic, visceromotor, and endocrine systems, such as the basal forebrain cholinergic system and locus ceruleus noradrenergic system, which project back to mPFC areas (Vogt et al., 1992; Devinsky et al., 1995; Drevets and Raichle, 1998; Whalen et al., 1998), thus corroborating an affective role for the rACC. By assessing the emotional salience of the $\mathrm{CS}$, the rACC may, via direct or indirect neuromodulatory inputs to other brain regions including the $\mathrm{ACC}$ and PL, allocate attentional resources to emotionally arousing stimuli and adapt/ strengthen existing memory networks (Fig. 10). In particular, evidence exists that rACC lesions do not affect acquisition but impair extinction of trace EBC (Weible et al., 2000). The rACC, by influencing arousal states and activity of other regions (e.g., cACC), may modulate sensitivity to behaviorally relevant stimuli and orient the functional state of the MPFC into a mode appropriate for the task at hand. As the emotional value of the stimulus decreases on repeated presentations within each session, there is less need for the rACC to maintain a constant drive, thus a decrease in activity as we and others have observed. Consequently, the loss of rACC functioning may lead to an inability to orient and modulate existing mPFC networks, thus accounting for the inability of conditioned animals to extinguish CS-US associations in response to CS-alone presentations.

Other interpretations for this phasic activity observed in the rACC are possible. For example, this pattern of activity may reflect a decrease in attention within a session. However, if this activity was correlated with attention, it should also be reflected in behavioral performance, i.e., animals should exhibit phasic decreases in trials in which CRs are elicited. Given that animals continue to exhibit CRs once they learn the CS-US association and do not exhibit phasic decreases in CRs within sessions, this interpretation is unlikely. Nonetheless, other interpretations are possible, and future studies of the rACC may provide more insight on these possibilities.

Although the present results were obtained and examined within the context of mnemonic processes, we believe that our results apply to other proposed functions of the mPFC. Holistically, the mPFC has been implicated for various roles besides mnemonic processes, including decision making, conflict monitoring, error detection, and executive control (Gemba et al., 1986; Picard and Strick, 1996; Drevets and Raichle, 1998; Posner and DiGirolamo, 1998; Carter et al., 1999; Euston et al., 2012). To reconcile these disparate views, Euston et al. (2012) have proposed a unifying theory that posits that the role of the $\mathrm{mPFC}$ is to integrate inputs regarding current context and events and output the most adaptive response based on past experience. We believe that our findings are in agreement with this view and provide electrophysiological support for this model. The functional reorganization we observed as manifested by the changes in activity within the three mPFC subregions as learning and memory consolidation proceeds underscores the roles of the individual $\mathrm{mPFC}$ subregions. They provide insight into how these subdivisions in- 
teract and work together to mediate the integration of inputs and modulation of other brain regions.

In summary, the present study provides, for the first time, longitudinal insight into the neurophysiological organization of three subdivisions of the mPFC during a cognitively demanding associative memory task. These data help to elucidate the normal response patterns occurring within the $\mathrm{MPFC}$ during acquisition and execution of remotely acquired behaviors. Future research can build on these findings, possibly through simultaneous $\mathrm{mPFC}$ subdivision recordings during other cognitively demanding tasks.

\section{References}

Blum S, Hebert AE, Dash PK (2006) A role for the prefrontal cortex in recall of recent and remote memories. Neuroreport 17:341-344. CrossRef Medline

Bruno RM, Simons DJ (2002) Feedforward mechanisms of excitatory and inhibitory cortical receptive fields. J Neurosci 22:10966-10975. Medline

Buckner RL, Wheeler ME (2001) The cognitive neuroscience of remembering. Nat Rev Neurosci 2:624-634. CrossRef Medline

Bush G, Whalen PJ, Rosen BR, Jenike MA, McInerney SC, Rauch SL (1998) The counting Stroop: an interference task specialized for functional neuroimaging - validation study with functional MRI. Hum Brain Mapp 6:270-282. CrossRef Medline

Bush G, Frazier JA, Rauch SL, Seidman LJ, Whalen PJ, Jenike MA, Rosen BR, Biederman J (1999) Anterior cingulate cortex dysfunction in attentiondeficit/hyperactivity disorder revealed by fMRI and the Counting Stroop. Biol Psychiatry 45:1542-1552. CrossRef Medline

Bush G, Luu P, Posner MI (2000) Cognitive and emotional influences in anterior cingulate cortex. Trends Cogn Sci 4:215-222. CrossRef Medline

Bussey TJ, Muir JL, Everitt BJ, Robbins TW (1996) Dissociable effects of anterior and posterior cingulate cortex lesions on the acquisition of a conditional visual discrimination: facilitation of early learning vs. impairment of late learning. Behav Brain Res 82:45-56. CrossRef Medline

Carter CS, Botvinick MM, Cohen JD (1999) The contribution of the anterior cingulate cortex to executive processes in cognition. Rev Neurosci 10:49-57. Medline

Choi DC, Maguschak KA, Ye K, Jang SW, Myers KM, Ressler KJ (2010) Prelimbic cortical BDNF is required for memory of learned fear but not extinction or innate fear. Proc Natl Acad Sci U S A 107:2675-2680. CrossRef Medline

Christian KM, Thompson RF (2005) Long-term storage of an associative memory trace in the cerebellum. Behav Neurosci 119:526-537. CrossRef Medline

Churchwell JC, Morris AM, Musso ND, Kesner RP (2010) Prefrontal and hippocampal contributions to encoding and retrieval of spatial memory. Neurobiol Learn Mem 93:415-421. CrossRef Medline

Clark RE, Squire LR (1998) Classical conditioning and brain systems: the role of awareness. Science 280:77-81. CrossRef Medline

Corcoran KA, Quirk GJ (2007) Activity in prelimbic cortex is necessary for the expression of learned, but not innate, fears. J Neurosci 27:840-844. CrossRef Medline

Das S, Weiss C, Disterhoft JF (2001) Eyeblink conditioning in the rabbit (Oryctolagus cuniculus) with stimulation of the mystacial vibrissae as a conditioned stimulus. Behav Neurosci 115:731-736. CrossRef Medline

Devinsky O, Morrell MJ, Vogt BA (1995) Contributions of anterior cingulate cortex to behaviour. Brain 118:279-306. CrossRef Medline

Dobbins IG, Foley H, Schacter DL, Wagner AD (2002) Executive control during episodic retrieval: multiple prefrontal processes subserve source memory. Neuron 35(5):989-996. CrossRef

Drevets WC, Raichle ME (1998) Reciprocal suppression of regional cerebral blood flow during emotional versus higher cognitive processes: implications for interactions between emotion and cognition. Cogn Emotion 12:353-385. CrossRef

Euston DR, Gruber AJ, McNaughton BL (2012) The role of medial prefrontal cortex in memory and decision making. Neuron 76:1057-1070. CrossRef Medline

Flores LC, Disterhoft JF (2013) Caudate nucleus in retrieval of trace eyeblink conditioning after consolidation. J Neurosci 33:2828-2836. CrossRef Medline
Frankland PW, Bontempi B (2006) Fast track to the medial prefrontal cortex. Proc Natl Acad Sci U S A 103:509-510. CrossRef Medline

Frankland PW, Bontempi B, Talton LE, Kaczmarek L, Silva AJ (2004) The involvement of the anterior cingulate cortex in remote contextual fear memory. Science 304:881-883. CrossRef Medline

Gabriel M (1990) Functions of anterior and posterior cingulate cortex during avoidance learning in rabbits. Prog Brain Res 85:467-482; discussion 482-483. Medline

Galvez R, Weiss C, Weible AP, Disterhoft JF (2006) Vibrissa-signaled eyeblink conditioning induces somatosensory cortical plasticity. J Neurosci 26:6062-6068. CrossRef Medline

Gemba H, Sasaki K, Brooks VB (1986) "Error" potentials in limbic cortex (anterior cingulate area 24) of monkeys during motor learning." Neurosci Lett 70:223-227.

Kalmbach BE, Ohyama T, Kreider JC, Riusech F, Mauk MD (2009) Interactions between prefrontal cortex and cerebellum revealed by trace eyelid conditioning. Learn Mem 16:86-95. CrossRef Medline

Kiani R, Esteky H, Tanaka K (2005) Differences in onset latency of macaque inferotemporal neural responses to primate and non-primate faces. J Neurophysiol 94:1587-1596. CrossRef Medline

Knuttinen MG, Power JM, Preston AR, Disterhoft JF (2001) Awareness in classical differential eyeblink conditioning in young and aging humans. Behav Neurosci 115:747-757. CrossRef Medline

Kronforst-Collins MA, Disterhoft JF (1998) Lesions of the caudal area of rabbit medial prefrontal cortex impair trace eyeblink conditioning. Neurobiol Learn Mem 69:147-162. CrossRef Medline

Lee I, Solivan F (2008) The roles of the medial prefrontal cortex and hippocampus in a spatial paired-association task. Learn Mem 15:357-367. CrossRef Medline

Manns JR, Clark RE, Squire L (2001) Single-cue delay eyeblink conditioning is unrelated to awareness. Cogn Affect Behav Neurosci 1:192-198. CrossRef Medline

Maviel T, Durkin TP, Menzaghi F, Bontempi B (2004) Sites of neocortical reorganization critical for remote spatial memory. Science 305:96-99. CrossRef Medline

Miller EK, Cohen JD (2001) An integrative theory of prefrontal cortex function. Annu Rev Neurosci 24:167-202. CrossRef Medline

Moscovitch M (1992) Memory and working-with-memory: a component process model based on modules and central systems. J Cogn Neurosci 4:257-267. CrossRef Medline

Ng CW, Noblejas MI, Rodefer JS, Smith CB, Poremba A (2007) Double dissociation of attentional resources: prefrontal versus cingulate cortices. J Neurosci 27:12123-12131. CrossRef Medline

Oswald BB, Maddox SA, Powell DA (2008) Prefrontal control of trace eyeblink conditioning in rabbits: role in retrieval of the CR? Behav Neurosci 122:841-848. CrossRef Medline

Oswald BB, Knuckley B, Mahan K, Sanders C, Powell DA (2009) Prefrontal control of trace eyeblink conditioning in rabbits (Oryctolagus cuniculus) II: effects of type of unconditioned stimulus (airpuff vs. periorbital shock) and unconditioned stimulus intensity. Physiol Behav 96:67-72. CrossRef Medline

Oswald BB, Maddox SA, Tisdale N, Powell DA (2010) Encoding and retrieval are differentially processed by the anterior cingulate and prelimbic cortices: a study based on trace eyeblink conditioning in the rabbit. Neurobiol Learn Mem 93:37-45. CrossRef Medline

Phan KL, Wager T, Taylor SF, Liberzon I (2002) Functional neuroanatomy of emotion: a meta-analysis of emotion activation studies in PET and fMRI. Neuroimage 16:331-348. CrossRef Medline

Phan KL, Liberzon I, Welsh RC, Britton JC, Taylor SF (2003) Habituation of rostral anterior cingulate cortex to repeated emotionally salient pictures. Neuropsychopharmacology 28:1344-1350. CrossRef Medline

Picard N, Strick PL (1996) Motor areas of the medial wall: a review of their location and functional activation. Cereb Cortex 6:342-353. CrossRef Medline

Posner MI, DiGirolamo GJ (1998) Executive attention: conflict, target detection and cognitive control. In: The attentive brain, pp 401-423. Cambridge, MA: Massachusetts Institute of Technology Press.

Postle BR (2006) Working memory as an emergent property of the mind and brain. Neuroscience 139:23-38. CrossRef Medline

Preston AR, Eichenbaum H (2013) Interplay of hippocampus and prefrontal cortex in memory. Curr Biol 23:R764-R773. CrossRef Medline

Quinn JJ, Ma QD, Tinsley MR, Koch C, Fanselow MS (2008) Inverse tem- 
poral contributions of the dorsal hippocampus and medial prefrontal cortex to the expression of long-term fear memories. Learn Mem 15:368 372. CrossRef Medline

Ranck JB Jr (1973) Studies on single neurons in dorsal hippocampal formation and septum in unrestrained rats. I. Behavioral correlates and firing repertoires. Exp Neurol 41:461-531. Medline

Richmond BJ, Optican LM, Podell M, Spitzer H (1987) Temporal encoding of two-dimensional patterns by single units in primate inferior temporal cortex. I. Response characteristics. J Neurophysiol 57:132-146. Medline

Runyan JD, Moore AN, Dash PK (2004) A role for prefrontal cortex in memory storage for trace fear conditioning. J Neurosci 24:1288-1295. CrossRef Medline

Siegel JJ, Mauk MD (2013) Persistent activity in prefrontal cortex during trace eyelid conditioning: dissociating responses that reflect cerebellar output from those that do not. J Neurosci 33:15272-15284. CrossRef Medline

Siegel JJ, Kalmbach B, Citwood RA, Mauk MD (2012) Persistent activity in a cortical-to-subcortical circuit: bridging the temporal gap in trace eyelid conditioning. J Neurophysiol 107:50-64. CrossRef Medline

Szucs A (1998) Applications of the spike density function in analysis of neuronal firing patterns. J Neurosci Methods 81:159-167. CrossRef Medline

Takehara K, Kawahara S, Kirino Y (2003) Time-dependent reorganization of the brain components underlying memory retention in trace eyeblink conditioning. J Neurosci 23:9897-9905. Medline

Takehara-Nishiuchi K, McNaughton BL (2008) Spontaneous changes of neocortical code for associative memory during consolidation. Science 322:960-963. CrossRef Medline

Teixeira CM, Pomedli SR, Maei HR, Kee N, Frankland PW (2006) Involvement of the anterior cingulate cortex in the expression of remote spatial memory. J Neurosci 26:7555-7564. CrossRef Medline

Totah NK, Kim YB, Homayoun H, Moghaddam B (2009) Anterior cingulate neurons represent errors and preparatory attention within the same behavioral sequence. J Neurosci 29:6418-6426. CrossRef Medline
Vogt BA, Finch DM, Olson CR (1992) Functional heterogeneity in cingulate cortex: the anterior executive and posterior evaluative regions. Cereb Cortex 2:435-443. CrossRef Medline

Weible AP, McEchron MD, Disterhoft JF (2000) Cortical involvement in acquisition and extinction of trace eyeblink conditioning. Behav Neurosci 114:1058-1067. CrossRef Medline

Weible AP, Weiss C, Disterhoft JF (2003) Activity profiles of single neurons in caudal anterior cingulate cortex during trace eyeblink conditioning in the rabbit. J Neurophysiol 90:599-612. CrossRef Medline

Weible AP, Weiss C, Disterhoft JF (2007) Connections of the caudal anterior cingulate cortex in rabbit: neural circuitry participating in the acquisition of trace eyeblink conditioning. Neuroscience 145:288-302. CrossRef Medline

Weible AP, Rowland DC, Monaghan CK, Wolfgang NT, Kentros CG (2012) Neural correlates of long-term object memory in the mouse anterior cingulate cortex. J Neurosci 32:5598-5608. CrossRef Medline

Weiss C, Disterhoft JF (1996) Eyeblink conditioning, motor control, and the analysis of limbic-cerebellar interactions. Behav Brain Sci 19:479_ 481. CrossRef

Weiss C, Disterhoft JF (2011) Exploring prefrontal cortical memory mechanisms with eyeblink conditioning. Behav Neurosci 125:318-326. CrossRef Medline

Weiss C, Kronforst-Collins MA, Disterhoft JF (1996) Activity of hippocampal pyramidal neurons during trace eyeblink conditioning. Hippocampus 6:192-209. CrossRef Medline

Weiss C, Weible AP, Galvez R, Disterhoft JF (2006) Forebrain-cerebellar interactions during learning. CellScience Rev 3:200-231.

Whalen PJ, Bush G, McNally RJ, Wilhelm S, McInerney SC, Jenike MA, Rauch SL (1998) The emotional counting Stroop paradigm: a functional magnetic resonance imaging probe of the anterior cingulate affective division. Biol Psychiatry 44:1219-1228. CrossRef Medline 